\title{
THE LONG-RUN IMPACT OF NEW MEDICAL IDEAS ON CANCER SURVIVAL AND MORTALITY
}

\author{
Frank R. Lichtenberg \\ Working Paper 25328 \\ http://www.nber.org/papers/w25328
NATIONAL BUREAU OF ECONOMIC RESEARCH
1050 Massachusetts Avenue
Cambridge, MA 02138
December 2018

The views expressed herein are those of the author and do not necessarily reflect the views of the National Bureau of Economic Research.

NBER working papers are circulated for discussion and comment purposes. They have not been peer-reviewed or been subject to the review by the NBER Board of Directors that accompanies official NBER publications.

(C) 2018 by Frank R. Lichtenberg. All rights reserved. Short sections of text, not to exceed two paragraphs, may be quoted without explicit permission provided that full credit, including () notice, is given to the source. 
The Long-run Impact of New Medical Ideas on Cancer Survival and Mortality

Frank R. Lichtenberg

NBER Working Paper No. 25328

December 2018

JEL No. I1,J11,O3

\begin{abstract}
$\underline{\text { ABSTRACT }}$
I investigate whether the types of cancer (breast, colon, lung, etc.) subject to greater penetration of new ideas had larger subsequent survival gains and mortality reductions, controlling for changing incidence. I use the MEDLINE/PubMED database, which contains more than 23 million references to journal articles published in 5400 leading biomedical journals, to construct longitudinal measures of the penetration of new medical ideas.

The 5-year survival rate is strongly positively related to the novelty of ideas in articles published 12-24 years earlier. This finding is consistent with evidence from case studies that it takes a long time for research evidence to reach clinical practice. The estimates suggest that about $70 \%$ of the 1994-2008 increase in the 5-year observed survival rate for all cancer sites combined may have been due to the increase in the novelty of medical ideas $12-24$ years earlier.

The number of years of potential life lost from cancer before ages 80 and 70 are inversely related to the novelty of ideas in articles published 12-24 years earlier, conditional on incidence. The increase in medical idea novelty was estimated to have caused a $38 \%$ decline in the premature (before age 80 ) cancer mortality rate $12-24$ years later.
\end{abstract}

Frank R. Lichtenberg

Columbia University

504 Uris Hall

3022 Broadway

New York, NY 10027

and NBER

frl1@columbia.edu 


\section{Introduction}

Longevity increase is a very important part of economic growth, broadly defined. Nordhaus (2005) argued that "improvements in health status have been a major contributor to economic welfare over the twentieth century. To a first approximation, the economic value of increases in longevity in the last hundred years is about as large as the value of measured growth in non-health goods and services.” Murphy and Topel (2006) estimated that cumulative gains in life expectancy after 1900 were worth over \$1.2 million to the representative American in 2000, whereas post-1970 gains added about \$3.2 trillion per year to national wealth, equal to about half of GDP. The United Nations' Human Development Index, which is used to rank countries into four tiers of human development, is a composite statistic of life expectancy, income per capita, and education (United Nations (2017)).

There is a consensus among macroeconomists that technological progress is the principal source of GDP growth. Romer (1990) argued that "growth...is driven by technological change that arises from intentional investment decisions made by profit-maximizing agents” (S71). Jones argued that "long-run growth is driven by the discovery of new ideas throughout the world." ${ }^{1,2}$ And Chien (2015) said that "it has been shown, both theoretically and empirically, that technological progress is the main driver of long-run growth.”

Since technological progress, or the discovery of new ideas, is the fundamental source of one of the major components_-GDP growth—of "human development," or economic growth, broadly defined, it is quite plausible that the discovery of new ideas has also played a major role in longevity growth. Some previous authors have suggested that this is the case. Fuchs (2010) said that "since World War II...biomedical innovations (new drugs, devices, and procedures) have been the primary source of increases in longevity," although he did not provide evidence to support this claim. Cutler, Deaton and Lleras-Muney (2006) performed a survey of a large and diverse literature on the determinants of mortality, and "tentatively identif[ied] the application of

\footnotetext{
${ }^{1}$ Sobel (1995) provides an excellent account of a specific innovation that had a substantial positive impact on economic growth: the development (by John Harrison, an 18th-century clockmaker) of the first clock (chronometer) sufficiently accurate to be used to determine longitude at sea—an important development in navigation.

${ }^{2}$ The discovery of new ideas could increase economic output for two different reasons. First, output could simply be positively related to the quantity (and variety) of ideas ever discovered. Second, output could be positively related to the (mean or maximum) quality of ideas ever discovered, and new ideas may be better (of higher quality), on average, than old ideas. As noted by Jovanovic and Yatsenko (2012), in "the Spence-Dixit-Stiglitz tradition...new goods [are] of higher quality than old goods.”
} 
scientific advance and technical progress (some of which is induced by income and facilitated by education) as the ultimate determinant of health." They concluded that "knowledge, science, and technology are the keys to any coherent explanation” of mortality.

In this paper, I will test the hypothesis that the arrival of new medical ideas ${ }^{3,4}$ has played a major role in the long-run increase in U.S. cancer survival and decline in cancer mortality. ${ }^{5} \mathrm{~A}$ difference-in-differences research design will be used: I will investigate whether types of cancer (breast, colon, lung, etc.) subject to greater penetration of new ideas had larger survival gains and mortality reductions, controlling for changing incidence.

I will allow for substantial lags in the relationship between new ideas and cancer patient outcomes; evidence from numerous case studies indicates that it takes a long time for research evidence to reach clinical practice. Morris, Wooding, and Grant (2011) reviewed 23 studies that quantified time lags in the development of health interventions. One study estimated that the time lag from publication of a clinical trial of a treatment for acute myocardial infarction to the establishment of a guideline/recommendation was between 6 and 13 years. Another study estimated a mean time lag from drug discovery to commercialization of 9 years. Balas and Bohen (2000), Grant et al (2003) and Wratschko (2009) all estimated a time lag of 17 years, measuring different points of the process. ${ }^{6}$

Cancer provides a good opportunity to study the impact of new ideas on mortality, for two reasons. First, as shown in Figure 1, in 2015 cancer was the leading cause of an important mortality measure: the number of years of potential life lost before age 80 (YPLL80). It was the

\footnotetext{
${ }^{3}$ Some ideas that are new in medicine may not be completely new. Gelijns and Rosenberg (1994) argued that “a high percentage of new medical devices have emerged not out of biomedical research, but through transfer of technologies that were developed elsewhere: lasers, ultrasound, magnetic resonance spectroscopy, and that most general-purpose of all technologies, the computer. Both the modern intensive care unit, with its dependence upon elaborate monitoring technologies, and much medical research itself have been based upon new capabilities acquired through transfer and subsequent modification to suit the particular needs of the medical sector.”

${ }^{4}$ For a new medical idea, or invention, to have an impact on health, the idea must be implemented. An invention that is licensed is likely to have a greater impact on health than one that is not licensed. Ali and Gittelman (2016) demonstrated that inventions by teams composed of clinical researchers (MDs) are more likely to be licensed than inventions by teams of basic scientists (PhDs); inventions that include both MDs and PhDs are not more likely to be licensed.

${ }^{5}$ Survival and mortality are not "mirror images" of each other. Survival measures (e.g. the 5-year survival rate) are conditional upon diagnosis, whereas mortality measures are not, although I will control, in an unrestrictive manner, for cancer incidence in the mortality analysis. Also, survival data are based on a sample (only people residing in SEER 9 cancer registry regions are included), whereas mortality data are derived from a census of all deaths. ${ }^{6}$ Unlike the present study, the endpoints in those studies were not health outcomes (e.g. mortality or survival); they were events such as establishment of a guideline or drug marketing approval.
} 
cause of 6.3 million YPLL80. It accounted for 22\% of YPLL80 from all causes, and 39\% more YPLL80 than the second highest cause, heart disease. ${ }^{7,8}$ Second, due to the existence of cancer registries, I can control for changes in the number of people diagnosed and their characteristics (e.g. their mean age). Incidence data are not available for most other diseases.

I will use the MEDLINE/PubMED database to construct measures of the penetration of new medical ideas applied to most types of cancer over time. MEDLINE/PubMED is the U.S. National Library of Medicine’s (NLM’s) premier bibliographic database; it contains more than 23 million references to journal articles published since 1946 in 5400 of the world's leading biomedical journals. A distinctive feature of MEDLINE/PubMED is that the records are indexed with Medical Subject Headings (MeSH). MeSH is the NLM's controlled vocabulary thesaurus; the NLM says that MeSH "is one of the most highly sophisticated thesauri in existence today."9 It consists of sets of terms (“descriptors”) in a hierarchical structure that permits searching at various levels of specificity. ${ }^{10}$ There were 27,883 descriptors in 2016 MeSH. ${ }^{11}$ Figure 2 shows the distribution of MeSH descriptors by major branch of the MeSH tree. ${ }^{12}$ Chemicals and Drugs (branch D) is the largest by far, accounting for 37.7\% of descriptors; Analytical, Diagnostic and Therapeutic Techniques, and Equipment [branch E] is the fourth largest, accounting for 8.6\% of descriptors.

The MeSH Section staff continually revise and update the MeSH vocabulary. ${ }^{13}$ Staff subject specialists are responsible for areas of the health sciences in which they have knowledge and expertise. In addition to receiving suggestions from indexers and others, the staff collect new terms as they appear in the scientific literature or in emerging areas of research; define these

\footnotetext{
${ }^{7}$ Cancer was the second highest cause of YPLL70, but it was a close second; it caused 99\% as many YPLL70 as the highest cause, unintentional injury.

${ }^{8}$ In view of the importance of cancer as a cause of premature mortality, it is not surprising that Murphy and Topel estimated that "a 1 percent reduction in cancer mortality would be worth $\$ 500$ billion."

${ }^{9}$ https://www.nlm.nih.gov/mesh/meshrels.html

${ }^{10}$ Most Descriptors indicate the subject of an indexed item, such as a journal article, that is, what the article is about. https://www.nlm.nih.gov/mesh/intro_record types.html. The MeSH "tree" can be explored here:

https://meshb.nlm.nih.gov/treeView.

${ }^{11}$ In addition to these headings, there are more than 232,000 Supplementary Concept Records (SCRs) within a separate file. Generally SCR records contain specific examples of chemicals, diseases, and drug protocols. They are updated more frequently than descriptors. Each SCR is assigned to a related descriptor via the Heading Map (HM) field. The HM is used to rapidly identify the most specific descriptor class and include it in the citation.

${ }^{12}$ A given descriptor can appear multiple times in the MeSH tree. For example, "Drug Therapy, ComputerAssisted" occurs in both branch E (Analytical, Diagnostic and Therapeutic Techniques, and Equipment) and branch L (Information Science).

${ }^{13}$ https://www.nlm.nih.gov/pubs/factsheets/mesh.html
} 
terms within the context of existing vocabulary; and recommend their addition to MeSH.

Professionals in various disciplines are also consulted regarding broad organizational changes and close coordination is maintained with various specialized vocabularies. As shown in Figure 3, between 1955 and 2015, the number of MeSH descriptors increased from 15.8 thousand to 27.8 thousand. On average, about 200 descriptors were added per year.

In Section II, I will describe the econometric models of cancer survival and mortality that I will estimate. The measurement of medical idea (MeSH descriptor) novelty will be discussed in Section III. Data sources and descriptive statistics will be presented in Section IV. Empirical results will be presented in Section V. The magnitude of the long-run impact of new ideas on cancer survival and mortality will be quantified in Section VI. Section VII provides a summary and conclusions.

\section{Econometric models of cancer survival and mortality}

I will estimate models of the 5-year observed survival rate and of several mortality measures using longitudinal cancer-site-level data. The survival rate model to be estimated is:

$$
\begin{aligned}
& \ln \left(\mathrm{SURV}_{-} \mathrm{OBS}_{\mathrm{st}} /\left(1-\mathrm{SURV} \_\mathrm{OBS} \mathrm{st}_{\mathrm{t}}\right)\right)=\beta_{\mathrm{k}} \mathrm{NEW} \_\mathrm{IDEAS} \mathrm{s}_{\mathrm{s}, \mathrm{t}-\mathrm{k}} \\
& \quad+\gamma \ln \left(\mathrm{SURV} \_\mathrm{EXP}_{\mathrm{st}} /\left(1-\mathrm{SURV} \_\mathrm{EXP} \mathrm{st}_{\mathrm{st}}\right)\right)+\pi \ln \left(\mathrm{N}_{-} \mathrm{DX} \mathrm{X}_{\mathrm{st}}\right)+\alpha_{\mathrm{s}}+\delta_{\mathrm{t}}+\varepsilon_{\mathrm{st}}
\end{aligned}
$$

where

SURV_OBS st $=$ the observed 5-year survival rate of patients diagnosed in SEER 9 registries with cancer at site $\mathrm{s}$ in year $\mathrm{t}\left(\mathrm{t}=1994,2008^{14}\right)$

NEW_IDEAS $S_{\mathrm{s}, \mathrm{t}-\mathrm{k}}=$ a measure of the novelty of ideas/descriptors in MEDLINE/PubMED articles about cancer at site $\mathrm{s}$ in year $\mathrm{t}-\mathrm{k}(\mathrm{k}=0,3,6, \ldots, 24)$

SURV_EXP st $_{\text {S }}=$ the expected 5-year survival rate of patients diagnosed in SEER 9 registries with cancer at site $\mathrm{s}$ in year $\mathrm{t}^{15}$

N_DX $=$ the number of patients diagnosed in SEER 9 registries with cancer at site $\mathrm{s}$ in year $\mathrm{t}$

\footnotetext{
${ }^{14}$ The 5-year survival rate is "forward-looking": the 5-year survival rate in 2008 is the fraction of patients diagnosed in 2008 who were alive at the end of 2013. 2008 is the most recent year for which data on the 5-year survival rate were available.

${ }^{15}$ The expected survival rate is the survival rate of cancer-free individuals of the same age, sex, and race as cancer patients.
} 


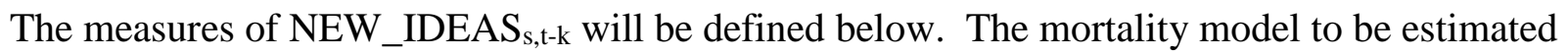
is:

$$
\begin{aligned}
& \ln \left(\mathrm{MORT}_{\mathrm{st}}\right)=\beta_{\mathrm{k}} \mathrm{NEW} \_\mathrm{IDEAS}, \mathrm{t}-\mathrm{k}+\gamma \ln \left(\mathrm{N} \_\mathrm{DX} \_10 \_\mathrm{YEAR}_{\mathrm{st}}\right) \\
& +\pi \text { AGE_DX_10_YEAR }{ }_{s t}+\alpha_{s}+\delta_{t}+\varepsilon_{s t}
\end{aligned}
$$

where $\mathrm{MORT}_{\mathrm{st}}$ is one of the following variables:

N_DEATHS ${ }_{\text {st }}=$ the number of deaths due to cancer at site $\mathrm{s}$ in year $\mathrm{t}(\mathrm{t}=1999,2013)$

YPLL80 $_{\text {st }}=$ the number of years of potential life lost before age 80 due to cancer at site $\mathrm{s}$ in year $\mathrm{t}$

YPLL70 $_{\text {st }}=$ the number of years of potential life lost before age 70 due to cancer at site $\mathrm{s}$ in year $\mathrm{t}$

The other variables in eq. (2) are

N_DX_10_YEAR st $_{\text {_ }}$ = the average annual number of people diagnosed with cancer at site $\mathrm{s}$ in years $\mathrm{t}-10$ to $\mathrm{t}-1$

AGE_DX_10_YEAR st $=$ the mean age at time of diagnosis of people diagnosed with cancer at site $\mathrm{s}$ in years $\mathrm{t}-10$ to $\mathrm{t}-1$

Eqs. (1) and (2) will be estimated via weighted-least squares. The weight for eq. (1) will be N_DX st; the weight for eq. (2) will be $(1 / \mathrm{T}) \sum_{\mathrm{t}} \mathrm{MORT}_{\text {st. }}$. Disturbances will be clustered within cancer sites.

From the fixed-effects models (eqs. (1) and (2)), we can derive "long-difference” models. For example, eq. (2) implies the following long-difference model of cancer mortality:

where

$$
\begin{array}{r}
\Delta \ln \left(\mathrm{MORT}_{\mathrm{s}}\right)=\beta_{\mathrm{k}} \Delta \mathrm{NEW} \_I D E A S \_\mathrm{k}_{\mathrm{s}}+\gamma \Delta \ln \left(\mathrm{N} \_\mathrm{DX} \_10 \_\mathrm{YEAR} \mathrm{S}_{\mathrm{s}}\right) \\
+\pi \Delta \mathrm{AGE} \_\mathrm{DX} \_10 \_\mathrm{YEAR}{ }_{\mathrm{s}}+\delta^{\prime}+\varepsilon_{\mathrm{s}}^{\prime}
\end{array}
$$

$$
\begin{aligned}
& \Delta \ln \left(\mathrm{MORT}_{\mathrm{s}}\right)=\ln \left(\mathrm{MORT}_{\mathrm{s}, 2013}\right)-\ln \left(\mathrm{MORT}_{\mathrm{s}, 1999}\right) \\
& \Delta \mathrm{NEW} \_I D E A S \_\mathrm{k}_{\mathrm{s}}=\mathrm{NEW} \_I D E A S_{\mathrm{s}, 2013-\mathrm{k}}-\mathrm{NEW} \_I D E A S_{\mathrm{s}, 1999-\mathrm{k}} \\
& \Delta \ln (\text { N_DX_10_YEAR })=\ln (\text { N_DX_10_YEAR }, 2013)-\ln \left(\text { N_DX_10_YEAR }_{s, 1999}\right)
\end{aligned}
$$




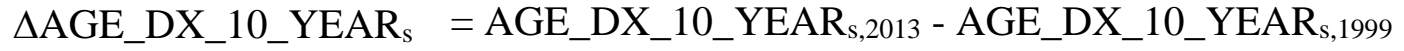

$$
\delta^{\prime}=\delta_{2013}-\delta_{1999}
$$

In Section V, I will present a graph (Figure 8) based on eq. (3).

\section{Measurement of idea/descriptor novelty}

One major branch (branch C) of the MeSH tree is the Diseases branch; it contains descriptors of thousands of diseases. By using these descriptors, we can identify all MEDLINE/PubMED articles that are about a particular disease, e.g. breast neoplasms. For each of those articles, we can determine the year of publication, and all of the descriptors assigned by the MeSH Section staff. A total of 247 million descriptors are assigned to the 27 million articles in MEDLINE/PubMED, so the average number of descriptors per article is 9.2.

One potential measure of idea novelty is the (frequency-weighted) mean vintage of $\mathrm{MeSH}$ descriptors used in articles about cancer at site s published in year t:

$$
\begin{aligned}
& \text { VINTAGE }_{\mathrm{st}}=\underline{\Sigma}_{\mathrm{d}} \text { FREQ }_{\mathrm{dst}}{ }_{\text {FIRST_YEAR }} \\
& \Sigma_{\mathrm{d}} \text { FREQ }_{\mathrm{dst}}
\end{aligned}
$$

where

VINTAGE $_{\text {st }} \quad=$ the (frequency-weighted) mean vintage of MeSH descriptors assigned to articles about cancer at site s published in year $\mathrm{t}$

FREQ $_{\mathrm{dst}}=$ the number of times MeSH descriptor $\mathrm{d}$ was assigned to articles about cancer at site s published in year $\mathrm{t}$

FIRST_YEAR $_{d} \quad=$ the first year in which MeSH descriptor d was assigned to any article in MEDLINE/PubMED

Because the time coverage of MEDLINE/PubMED is generally 1946 to the present, with some older material, the variable FIRST_YEAR ${ }_{d}$ is left-censored. ${ }^{16,17}$ Therefore, a measure like the

\footnotetext{
${ }^{16}$ The number of descriptors increased from 297 in 1944 to 11,205 in 1947.

${ }^{17}$ I calculated the vintage of each descriptor (FIRST_YEAR R $_{d}$ by determining the first year in which the descriptor occurred in the file containing 247 million descriptor records merged with publication dates. Two alternative potential methods of calculating the vintage of each descriptor did not yield reliable results. One of these methods is to use the DA (DATE OF ENTRY) field in the ASCII MeSH file. The other is to use the Medline citation counts by
} 
following, based on a binary function of FIRST_YEAR, may be more appropriate than a measure based on FIRST_YEAR itself:

$$
\text { POST1975\% } \%_{\mathrm{st}}=\underline{\Sigma}_{\mathrm{d}} \frac{\text { FREQ }}{\mathrm{dst}} \text { POST1975 }_{\mathrm{d}}
$$

where

$$
\begin{aligned}
& \text { POST1975\% } \%_{\text {st }}=\text { the (frequency-weighted) fraction of MeSH descriptors assigned to articles } \\
& \text { about cancer at site s published in year t that were established after } 1975 \\
& \text { POST1975d }=1 \text { if FIRST_YEAR }>1975 \\
& =0 \text { if FIRST_YEAR } \leq 1975
\end{aligned}
$$

The MeSH FTP Archive includes lists of new MeSH descriptors added each year since 1999. For example, one file shows MeSH descriptors added in 2016. Some new MeSH descriptors are not new ideas. For example, one MeSH descriptor added in 2016 was “Alcohol Drinking in College” (UI D000067292); this “idea” undoubtedly occurred to someone well before 2016. Hence, the relative frequency of new MeSH descriptors is a noisy, or imperfect, measure of the penetration of new medical ideas. If this measurement error is random, it will bias the coefficients on our measures of new ideas towards zero.

The MEDLINE/PubMED data provide us with an opportunity to assess the validity of MeSH descriptor novelty as an indicator of new ideas, or technological progress. Most scholars agree with Jones' (1998, pp.89-90) statement that “technological progress is driven by research and development (R\&D) in the advanced world.” It is possible to distinguish between MEDLINE/PubMED articles that resulted from research funding (when that financial support is mentioned in the articles) and MEDLINE/PubMED articles that did not result from (or mention) research funding. ${ }^{18}$ One would expect newer descriptors to be assigned to "research-based articles” than to "non-research-based” articles. Figure 4 shows the \% of descriptors in 2010

\footnotetext{
descriptor and year from the Unified Medical Language System. See https://www.nlm.nih.gov/research/umls/2006AA_umls_documentation.pdf

${ }^{18} \mathrm{MeSH}$ includes Publication Types to identify financial support of the research that resulted in the published papers when that support is mentioned in the articles. Three types of research support (Non-U.S. Gov't, U.S. Gov't--NonP.H.S., and U.S. Gov't--P.H.S.) have been coded since 1975; two types (N.I.H.--Extramural and N.I.H.--Intramural) have been coded since 2005; and one type (American Recovery \& Reinvestment Act) has been coded since 2010. Funding Support (Grant) Information in MEDLINE/PubMed.
} 
publications established after 1980, by type of research support. 4.5\% of the descriptors in 2010 “non-research” publications were established after 1980. 8.1\% of the descriptors in 2010 publications that mentioned non-government (but not government) research support were established after 1980. 8.8\% of the descriptors in 2010 publications that mentioned government (but not non-government) research support were established after 1980. And $10.5 \%$ of the descriptors in 2010 publications that mentioned both non-government and government research support were established after 1980. This evidence supports the hypothesis that newer descriptors are assigned to "research articles" than to "non-research" articles.

The vintage measure described above will be constructed using data on one MeSH record type: MeSH descriptors. Another MeSH record type is Supplementary Concept Records (SCRs). SCRs are used to index chemicals, drugs, and other concepts such as rare diseases. The vintage measure described above (POST1975\% st) can be constructed using both SCRs and descriptor records combined instead of using descriptor records alone. ${ }^{19}$

There are several reasons to believe that vintage measures based solely on descriptor records are more reliable than vintage measures based on both SCRs and descriptor records combined. The NLM says that descriptors "play a central role in MeSH vocabulary as a unit of indexing and retrieval”"20; they don't say that about SCRs. Descriptors seem to be more carefully curated than SCRs: descriptors are generally updated on an annual basis (but may, on occasion, be updated more frequently), while SCRs are created daily. Most importantly, vintage measures based on both SCRs and descriptor records combined may be subject to double-counting, since "each SCR is linked to one or more Descriptors by the Heading Mapped To (HM) field in the SCR."21

\section{Data sources and descriptive statistics}

Survival rate data for SEER 9 registries were obtained from SEER*Stat Software (Version 8.3.4).

\footnotetext{
${ }^{19}$ Although the number of SCR terms $(>230,000)$ is much greater than the number of descriptors (about 28,000), the number of descriptor records in PubMed cancer publications is more than 5 times as great as the number of SCRs.

${ }^{20}$ MeSH Record Types.

${ }^{21} 9$ of the 10 (and 19 of the 31) largest-selling cancer drugs (e.g. RITUXIMAB, BEVACIZUMAB) have descriptor records rather than SCRs. Other cancer drugs with SCRs are mapped to descriptor records. For example, NILOTINIB is mapped to Pyrimidines, and IPILIMUMAB is mapped to Antibodies, Monoclonal.
} 
Mortality data were obtained from the raw datafiles of the WHO Mortality Database, which is a compilation of mortality data by age, sex and cause of death, as reported annually by Member States from their civil registration systems.

MEDLINE/PubMed data were provided by Pierre Azoulay and Bhaven Sampat, who obtained and reformatted data from the NLM Bulk Download FTP site.

Cancer incidence data from SEER 9 registries were obtained from SEER research data, which include SEER incidence and population data associated by age, sex, race, year of diagnosis, and geographic areas (including SEER registry and county).

Population by age data were obtained from CDC Wonder Bridged-Race Population Estimates 1990-2013.

Disease classification. The disease (cancer site) classification used in the analysis was based on the SEER Cause of Death Recode 1969+. Appendix Table 1 shows the MeSH descriptors linked to SEER causes of death.

Observed and expected 5-year survival rates in 1994 and 2008 of patients diagnosed in SEER 9 registries, by cancer site ranked by descending number of patients diagnosed in 1994, are shown in Appendix Table 2.

Mortality and incidence data for 1999 and 2013, by cancer site ranked by descending YPLL80 in 1999, are shown in Appendix Table 3.

Figure 5 shows the percent of descriptors in 2013 articles that were established after 1980, by cancer site, for cancer sites with at least 10,000 descriptors in 2013. The percent of post-1980 descriptors in 2013 was almost twice as great for the top two cancer sites as it was for the bottom two.

Figure 6 shows the percent of cancer article descriptors that were less than 25 years old, by publication year (1995-2015). The new descriptor fraction exhibits a slight downward trend; it was 7.1\% during 1995-2005 and 6.3\% in 2010-2015. Bloom et al (2017) "present a wide range of evidence from various industries, products, and firms showing that research effort is rising substantially while research productivity is declining sharply.” The slight downward trend in the mean novelty of cancer publications may indicate that cancer research effort has not increased as much as cancer research productivity has declined. 


\section{Empirical results}

a. Survival model (eq. (1)) estimates

Estimates of $\beta_{\mathrm{k}}$ parameters of models of the 5-year observed survival rate (eq. (1)) are shown in Table 1. Each estimate is from a separate model. All models included

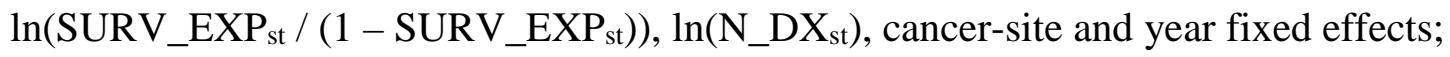
coefficients on these variables are not shown to conserve space. ${ }^{22}$ I estimated 6 sets of models; these sets varied with respect to (1) whether all cancer sites were included; (2) whether the NEW_IDEAS measure was based on descriptor records only or descriptor + supplementary concept records; and (3) the year threshold (e.g. 1975) for distinguishing between "new ideas" and "old ideas." For each set, I estimated the model for 9 different assumed lags $(0,3,6, \ldots, 24$ years) of NEW_IDEAS.

In Panel A of Table 5, all cancer sites are included; the NEW_IDEAS measure is based on descriptor records only; and the new-idea year threshold is 1975 . When the lag length $\mathrm{k} \leq 9$, the estimates of $\beta_{\mathrm{k}}$ are not statistically significant. However, when $\mathrm{k} \geq 12$, the estimates of $\beta_{\mathrm{k}}$ are positive and highly statistically significant. This indicates that the 5-year survival rate is not related to the novelty of ideas in (i.e. the fraction of post-1975 descriptors of) articles published 0-9 years earlier, but strongly related to the novelty of ideas in articles published 12-24 years earlier. This finding is consistent with the evidence from case studies cited above that it takes a long time for research evidence to reach clinical practice.

The estimates in Table 1 are weighted by the number of patients diagnosed, and as shown in Appendix Table 2, the cancer site with the largest number of patients diagnosed is prostate cancer. Although prostate cancer does not appear to be an outlier (e.g. with respect to NEW_IDEAS, as shown in Figure 5), some estimates suggested that it might be an influential observation. Panel B of Table 1 shows estimates of eq. (1) when prostate cancer is excluded. The point estimates of the parameters are somewhat smaller, but as in Panel A, when the lag length $\mathrm{k} \leq 9$, the estimates of $\beta_{\mathrm{k}}$ are not statistically significant, and when $\mathrm{k} \geq 12$, the estimates of $\beta_{\mathrm{k}}$ are positive and highly statistically significant.

${ }^{22}$ The coefficient on $\ln \left(\mathrm{SURV}_{\mathrm{EXX}} \mathrm{Est} /\left(1-\mathrm{SURV} \_E X P_{\mathrm{st}}\right)\right)$ was positive and significant in some, but not all, models. The coefficient on $\ln \left(\mathrm{N}_{-} \mathrm{DX} \mathrm{X}_{\mathrm{st}}\right)$ was insignificant in all models. 
In Panel C of Table 1, all cancer sites are included, and the NEW_IDEAS measure is based on descriptor + supplementary concept records. The same pattern emerges: estimates of $\beta_{\mathrm{k}}$ are positive and highly statistically significant only when $\mathrm{k} \geq 12$.

In Panel D, prostate cancer is excluded, and the NEW_IDEAS measure is based on descriptor + supplementary concept records. In this case, the $\beta_{15}$ and $\beta_{18}$ coefficients are statistically significant (the $\beta_{12}$ coefficient is marginally significant), but the $\beta_{21}$ and $\beta_{24}$ coefficients are insignificant. However, it may be inappropriate to exclude prostate cancer, ${ }^{23}$ and as discussed above, vintage measures based solely on descriptor records are probably more reliable than vintage measures based on both SCRs and descriptor records combined.

Panels $\mathrm{E}$ and $\mathrm{F}$ of Table 1 examine the sensitivity of the estimates to the choice of the year threshold for distinguishing between "new ideas” and “old ideas.” In Panel E, the year threshold is 1970; in Panel F, it is 1980. In both cases, estimates of $\beta_{\mathrm{k}}$ are positive and highly statistically significant only when $\mathrm{k} \geq 12$.

b. Mortality model (eq. (2)) estimates

Estimates of $\beta_{\mathrm{k}}$ parameters of models of mortality measures (eq. (2)) are shown in Table 2. Once again, each estimate is from a separate model. All models included ln(N_DX_10_YEAR $\left.{ }_{\text {st }}\right)$, AGE_DX_10_YEAR st, cancer-site and year fixed effects; coefficients on these variables are not shown to conserve space. ${ }^{24}$ I estimated 6 sets of models; these sets varied with respect to (1) the dependent variable (mortality measure); and (2) whether the NEW_IDEAS measure was based on descriptor records only or descriptor + supplementary concept records. In all models in Table 2, the year threshold for distinguishing between "new ideas” and “old ideas” was 1980. For each set, I estimated the model for 9 different assumed lags $(0,3,6, \ldots, 24$ years $)$.

In Panel A of Table 2, the dependent variable is $\ln$ (YPLL80) - the log of the number of years of potential life lost before age 80 . The estimated coefficient on POST1980\%s,t-k is not significant for $\mathrm{k} \leq 6$, but is negative and highly significant for $\mathrm{k} \geq 9$. This indicates that

\footnotetext{
${ }^{23}$ The fact that an observation is influential does not necessarily mean that it should be excluded.

${ }^{24}$ The coefficient on In(N_DX_10_YEAR st $_{\text {f }}$ was positive and highly significant in all models. The coefficient on AGE_DX_10_YEAR st $_{\text {t }}$ was negative and highly significant in the YPLL80 and YPLL70 models, and insignificant in the DEATHS models.
} 
premature (before age 80) mortality is inversely related to the fraction of descriptors established after 1980 9-24 years earlier. The estimates in Panel A are plotted in Figure 7. The relationship across cancer sites between the 1981-1995 change in POST1980\% and the 1999-2013 change in $\ln ($ YPLL80), controlling for changes in incidence, is shown in Figure 8.

The estimates in Panel A are weighted by mean YPLL80. As shown in Appendix Table 3, cancer of the lung and bronchus is the largest cause of YPLL80 by far, accounting for more than a quarter of the total, and almost three times as much as the second highest cause, breast cancer. But excluding cancer of the lung and bronchus has very little effect on the estimates. For example, estimates of $\beta_{18}$ when cancer of the lung and bronchus are included (as in Panel A) and excluded are $-10.92(Z=4.26)$ and $-10.83(Z=4.41)$, respectively. Changing the year threshold for distinguishing between "new ideas” and “old ideas” to either 1975 or 1985 also has little effect on the estimates.

In Panel B of Table 2, POST1980\% is based on descriptor + supplementary concept records. The estimates of $\beta_{\mathrm{k}}$ are negative and highly statistically significant only when $\mathrm{k} \geq 12$.

In panels $\mathrm{C}$ and $\mathrm{D}$ of Table 2, a lower age cutoff_-age 70 —is used for measuring premature mortality. The results are similar to those in Panels A and B, where the higher (age 80) age cutoff was used. In Panels E and F of Table 2, the dependent variable is the log of the number of deaths. The estimates indicate that the number of deaths is inversely related to the novelty of ideas published in articles 12-24 years earlier, conditional on the number of patients diagnosed 1-10 years before and their mean age at time of diagnosis.

\section{Discussion}

The estimates in Tables 1 and 2 are highly consistent with the hypothesis that the application of new ideas has increased cancer survival and reduced cancer mortality, with a significant lag. Now I will quantify the magnitude of these impacts.

The 1994-2008 change in the weighted (by number of patients diagnosed) mean value of the log-odds of the observed 5-year survival rate (ln(SURV_OBS st $_{\text {/ }}\left(1-\right.$ SURV_OBS $\left.\left._{\text {st }}\right)\right)$ ) was $0.527 .{ }^{25}$ The increase in the log-odds of survival attributable to the increasing share of post-1975

\footnotetext{
25 This is larger than the 0.371 increase in the log-odds of the survival rate for all cancer sites combined. That survival rate increased from $52.1 \%$ in 1994 to $61.2 \%$ in 2008.
} 
descriptors may be estimated by multiplying the estimated coefficients in Table 1 by the weighted mean change in the lagged share of post-1975 descriptors. Panel A of Table 3 shows these calculations using the statistically significant estimates in Panel A of Table 1.

The estimate of $\beta_{12}$ suggests that the increase in descriptor novelty 12 years earlier accounted for almost all $(94 \%=.496 / .527)$ of the increase in survival. The estimate of $\beta_{24}$ suggests that the increase in descriptor novelty 24 years earlier accounted for about half as much $(48 \%=.251 / .527)$ of the increase in survival. The average of the estimates for $12 \leq k \leq 24$ suggests that the increase in descriptor novelty $12-24$ years earlier accounted for $71 \%$ (= .372 / .527) of the increase in survival.

The 1999-2013 change in the weighted (by mean YPLL80) mean value of $\ln ($ YPLL80) was $0.045 .{ }^{26}$ During that period, the population below age 80 increased by $12.7 \%$, from 270.0 to 304.3 million, so that YPLL80 from cancer per person below age 80 declined by about $8.0 \%$. As shown in Panel B of Table 3, the average of the estimates for $9 \leq k \leq 24$ in Panel A of Table 2 suggests that the increase in descriptor novelty 9-24 years earlier resulted in a 26\% decline in YPLL80, and a 38\% decline in YPLL80 per person below age 80.

This is much larger than the actual (8\%) reduction in YPLL80 from cancer per person below age 80. This suggests that, if new ideas had not been applied to cancer, the premature (before age 80) cancer mortality rate would have increased significantly (by about 30\%) between 1999 and 2013. A possible explanation for this is declining competing risk from cardiovascular disease (Honoré and Lleras-Muney (2006)), although inclusion of cancer incidence measures in the mortality model may have controlled for this to some extent.

\section{Summary and conclusions}

I performed tests of the hypothesis that the arrival of new medical ideas has played a major role in the long-run increase in U.S. cancer survival and decline in cancer mortality, by investigating whether the types of cancer (breast, colon, lung, etc.) subject to greater penetration of new ideas had larger subsequent survival gains and mortality reductions, controlling for changing incidence.

\footnotetext{
${ }^{26}$ This is similar to the 0.040 log increase (from 6.06 to 6.31 million) indicated by Years of Potential Life Lost (YPLL) Reports, $1999-2015$.
} 
I used the MEDLINE/PubMED database, which contains more than 23 million references to journal articles published since 1946 in 5400 of the world's leading biomedical journals, to construct measures of the penetration of new medical ideas applied to most types of cancer over time. MEDLINE/PubMED records are indexed with Medical Subject Headings (MeSH), “one of the most highly sophisticated thesauri in existence today.” Between 1955 and 2015, the number of MeSH descriptors increased from 15.8 thousand to 27.8 thousand. Newer descriptors are assigned to "research articles” than to "non-research” articles.

The estimates indicated that the 5-year survival rate is not related to the novelty of ideas in (i.e. the fraction of post-1975 MeSH descriptors of) articles published 0-9 years earlier, but strongly positively related to the novelty of ideas in articles published 12-24 years earlier. This finding is consistent with evidence from case studies that it takes a long time for research evidence to reach clinical practice. Between 1994 and 2008, the 5-year observed survival rate for all cancer sites combined increased from 52.1\% to 61.2\%. The estimates suggest that about $70 \%$ of this increase may have been due to the increase in the novelty of medical ideas 12-24 years earlier.

The number of years of potential life lost from cancer before ages 80 and 70 and the number of cancer deaths are inversely related to the novelty of ideas in articles published 12-24 years earlier, conditional on the number of patients diagnosed 1-10 years before and their mean age at time of diagnosis. The increase in descriptor novelty was estimated to have caused a 38\% decline in the premature (before age 80 ) cancer mortality rate 12-24 years later. The fact that this is much larger than the actual (8\%) reduction in the premature cancer mortality rate may be due, in part, to declining competing risk from cardiovascular disease.

The econometric models estimated in this paper probably don't fully capture the rich complexity of biomedical innovation. As discussed by Gelijns and Rosenberg (1994):

The popular perception of medical innovation is one in which a group of biomedical scientists has a bright new idea, which then moves in a linear progression from the laboratory to animal models, to select populations, and finally to the bedside. Although much innovation in medicine flows in this fashion, this linear conceptualization captures only part of the reality, particularly with regard to medical devices.”

...much uncertainty associated with a new technology can be resolved only after extensive use in practice. Thus, development does not end with the adoption of an innovation. Actual adoption constitutes only the beginning of an often-prolonged process 
in which important redesigning takes place, exploiting the feedback of new information generated by users.

Our econometric analysis provided evidence about the clinical effectiveness of new medical ideas - their impact on health outcomes-but not on their cost-effectiveness-the ratio of their impact on $\operatorname{cost}^{27}$ to their impact on health outcomes. Evaluation of the latter using our framework would require reliable data on the average cost of treatment, by cancer site and year. The National Cancer Institute (2018) has published data on average annual treatment cost, by cancer site, but only during a single period (2001-2006). Moreover, Lipscomb (2008) argues that estimating the cost of cancer care in the United States is "a work very much in progress": "different experts have chosen different data sources and methods to evaluate a specific issue [in cancer care costing] and have ended up with different results." Evaluation of the costeffectiveness of new medical ideas for cancer (and other diseases) is a task for future research.

\section{References}

Ali A, Gittelman M. 2016. "Research paradigms and useful inventions in medicine: Patents and licensing by teams of clinical and basic scientists in Academic Medical Centers." Research Policy 45(8.: 1499-1511.

Balas EA, Boren SA. 2000. Yearbook of Medical Informatics: Managing Clinical Knowledge for Health Care Improvement. Stuttgart, Germany: Schattauer Verlagsgesellschaft mbH.

Bloom N, Jones CI, van Reenen J, Webb M. 2017. “Are Ideas Getting Harder to Find?” NBER Working Paper No. 23782, September, https://www.nber.org/papers/w23782

Chien YL. 2015. “What Drives Long-Run Economic Growth?” Federal Reserve Bank of St. Louis.

Cutler D, Deaton A, Lleras-Muney A. 2006. “The Determinants of Mortality.” Journal of Economic Perspectives 20(3.: 97-120, Summer.

Fuchs, VR. 2010., “New Priorities for Future Biomedical Innovations." New England Journal of Medicine 363: 704-706, August 19,

Gelijns A, Rosenberg N. 1994. “The Dynamics of Technological Change in Medicine.” Health Affairs 13(3).

${ }^{27}$ Gelijns and Rosenberg (1994) wrote that "technological change... has been widely identified as the principal culprit in the rising costs of medical care." 
Grant J, Green L, Mason B. 2003. "Basic research and health: a reassessment of the scientific basis for the support of biomedical science.” Research Evaluation 12 (3): 217-24, 1 December, https://doi.org/10.3152/147154403781776618

Greenwood, J., Z. Hercowitz, and P. Krusell. 1997. "Long-Run Implications of InvestmentSpecific Technological Change.” American Economic Review 87 (3): 342-62, June.

Grossman GM, Helpman E. 1991. "Quality Ladders in the Theory of Growth.” The Review of Economic Studies, 58(1): 43-61.

Hanney SR, Castle-Clarke S, Grant J, et al. 2015. “How long does biomedical research take? Studying the time taken between biomedical and health research and its translation into products, policy, and practice.” Health Research Policy and Systems 13:1. doi:10.1186/1478-4505-13-1.

Honoré BE, Lleras-Muney A. 2006. "Bounds in Competing Risks Models and the War on Cancer.” Econometrica 74(6): 1675-98, November.

Jones, CI. 1998. Introduction to Economic Growth. New York: W.W. Norton.

Jones CI. 2002. "Sources of U.S. Economic Growth in a World of Ideas.” American Economic Review 92(1): 220-39, March.

Jovanovic B, Yatsenko Y. 2012. “Investment in Vintage Capital.” Journal of Economic Theory, 147(2): 551-569.

Lipscomb J. 2008. "Estimating the Cost of Cancer Care in the United States: A Work Very Much in Progress.” JNCI: Journal of the National Cancer Institute 100(9): 607-10, 7 May.

Morris ZS, Wooding S, Grant J. 2011. “The answer is 17 years, what is the question: understanding time lags in translational research.” Journal of the Royal Society of Medicine 104(12): 510-20, December, https://doi.org/10.1258\%2Fjrsm.2011.110180

Murphy KM, Topel RH. 2006. “The Value of Health and Longevity.” Journal of Political Economy 114 (5): 871-904, October.

National Cancer Institute. 2018. “Annualized Mean Net Costs of Care per Patient.” https://costprojections.cancer.gov/annual.costs.html

Romer P. 1990. “Endogenous Technological Change.” Journal of Political Economy 98 (5), Part 2: S71-S102.

Sobel D. 1995. Longitude: The True Story of a Lone Genius Who Solved the Greatest Scientific Problem of His Time. New York: Bloomsbury.

Solow R. 1960. "Investment and Technological Progress.” In Mathematical methods in the social sciences, 1959, edited by K. Arrow, S. Karlin, and P. Suppes. Stanford, Calif: Stanford University Press. 
Westfall J, Mold J, Fagnan L. 2007. "Practice-based research - "Blue Highways” on the NIH roadmap.” Journal of the American Medical Association 297(4):403-6, January 24.

Wratschko K. 2009. Empirical Setting: The pharmaceutical industry. Strategic Orientation and Alliance Portfolio Configuration. New York, NY: Springer. 


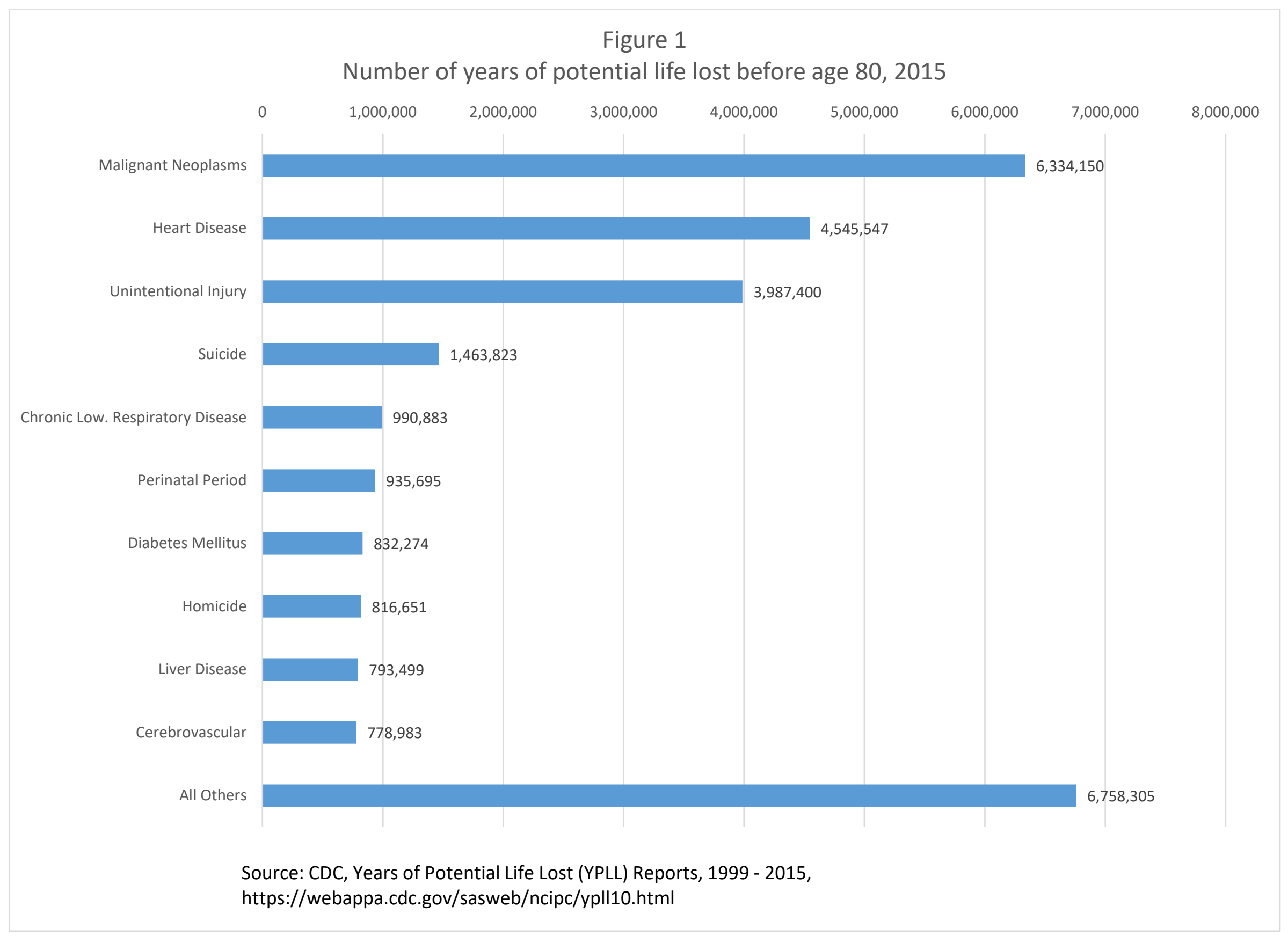




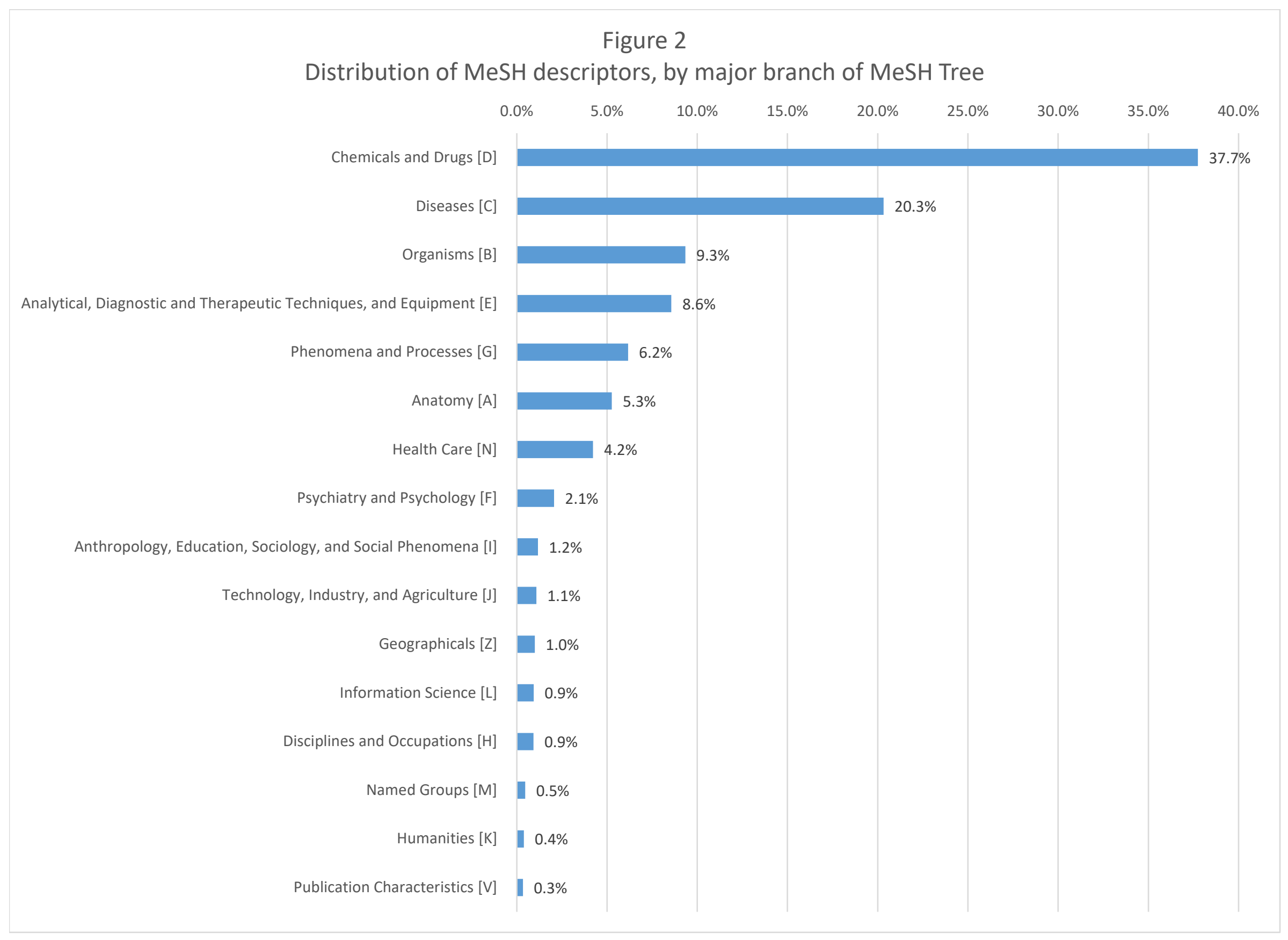


Figure 3

Number of MeSH descriptors ever established, 1955-2015

30,000

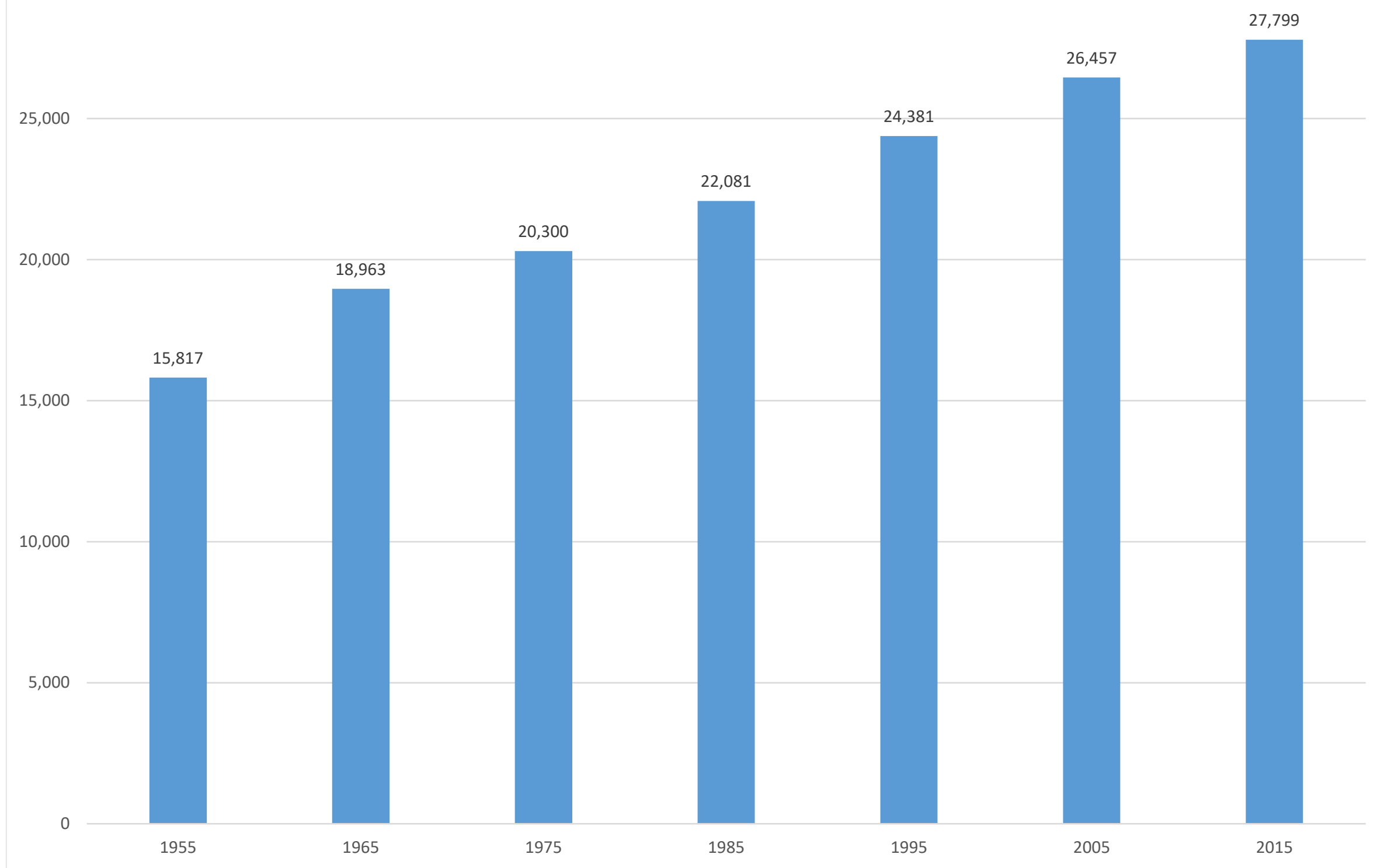


Figure 4

$\%$ of descriptors in 2010 publications established after 1980, by type of research support

$12 \%$

$10.5 \%$

$10 \%$

$8.8 \%$

$8 \%$

$8.1 \%$

$6 \%$

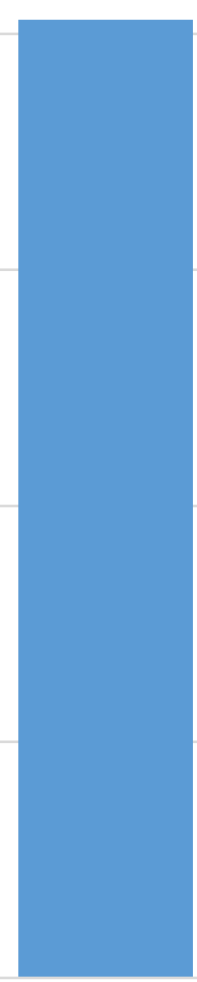

$0 \%$

$4.5 \%$

$4 \%$

$2 \%$

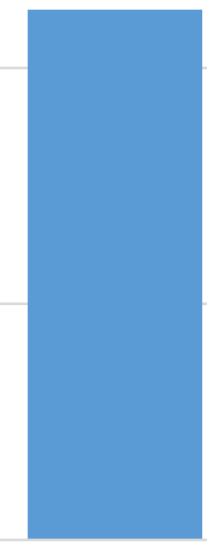

no research support

nongovernment research support only

U.S. government research support only

nongovernment \& U.S. government research support 


\section{Figure 5}

$\%$ of descriptors in 2013 articles that were established after 1980, by cancer site (cancer sites with at least 10,000 descriptors in 2013)

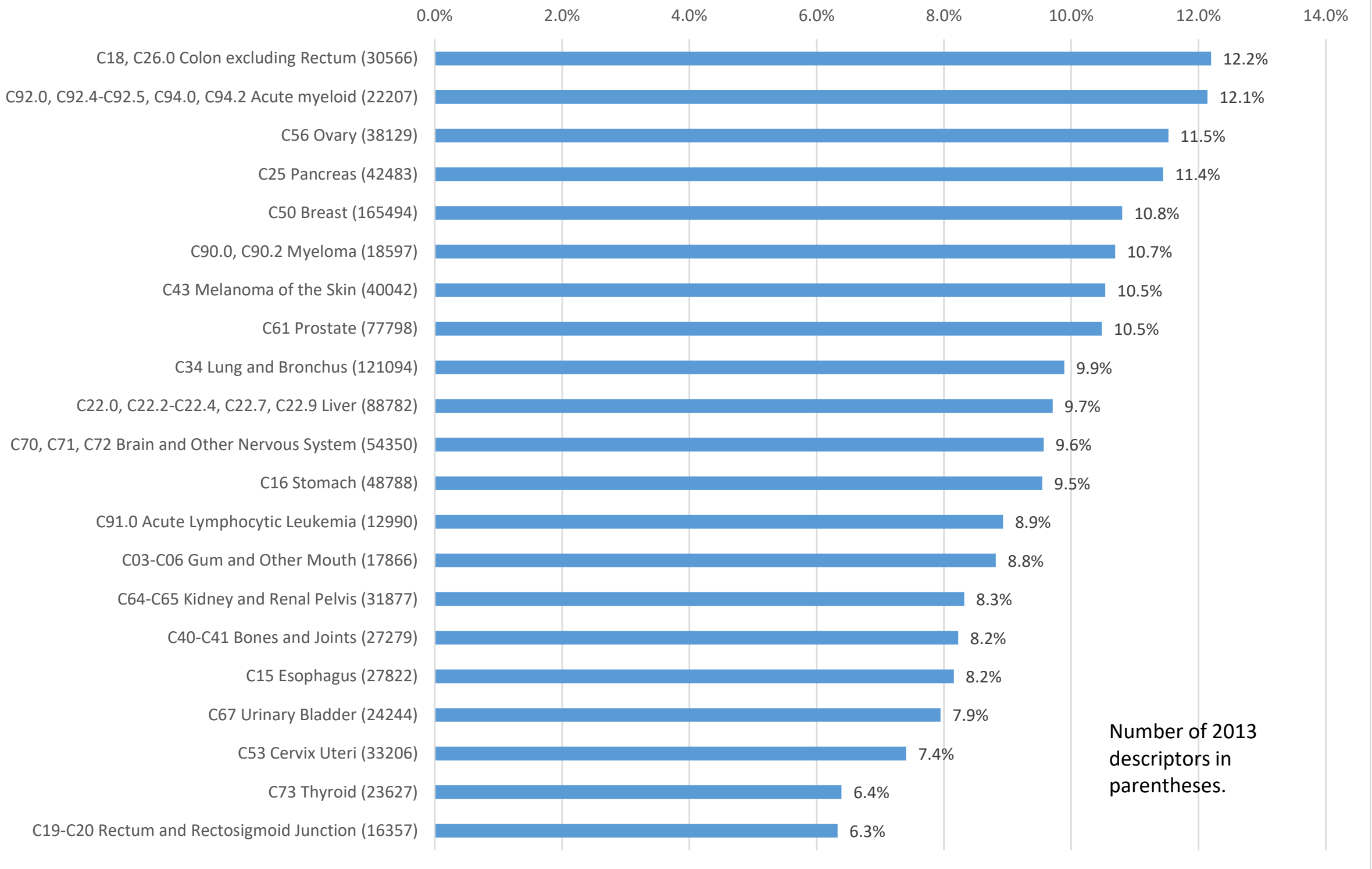


Figure 6

$\%$ of cancer article descriptors that were less than 25 years old, by publication year (1995-2015)

$9.0 \%$

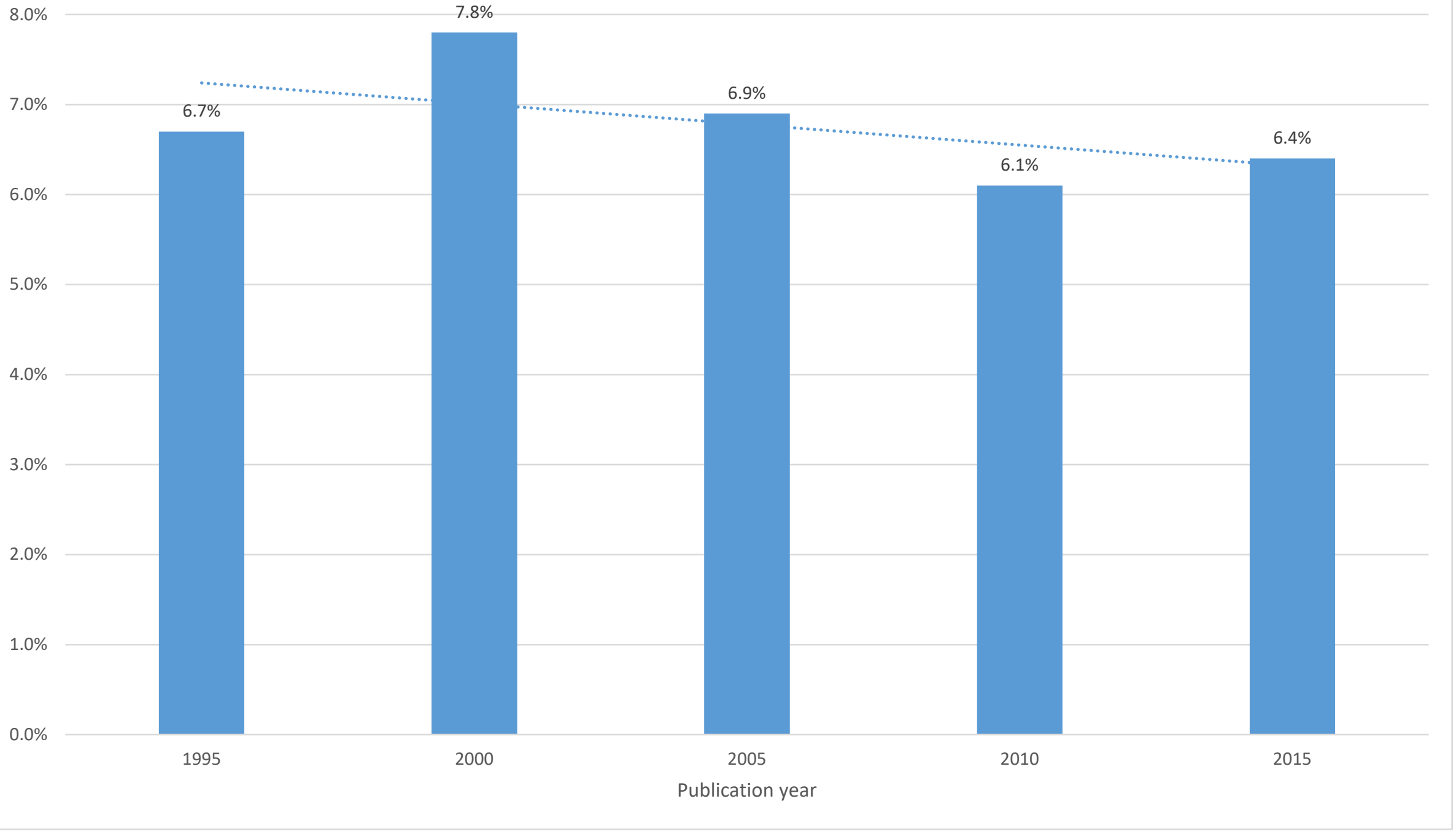


Figure 7

Estimates of $\beta_{\mathrm{k}}$ from the equation

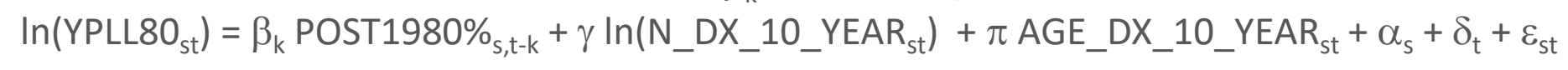

$-30$

$$
\mathrm{k} \text { (lag) }
$$

$$
-25
$$

$-20$

$-15$

$-10$

$\stackrel{2}{2}$

$-5$

0

10

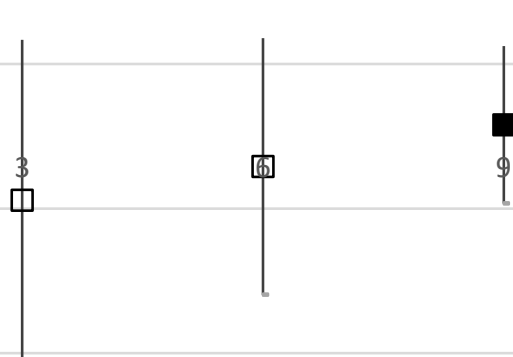

中

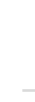

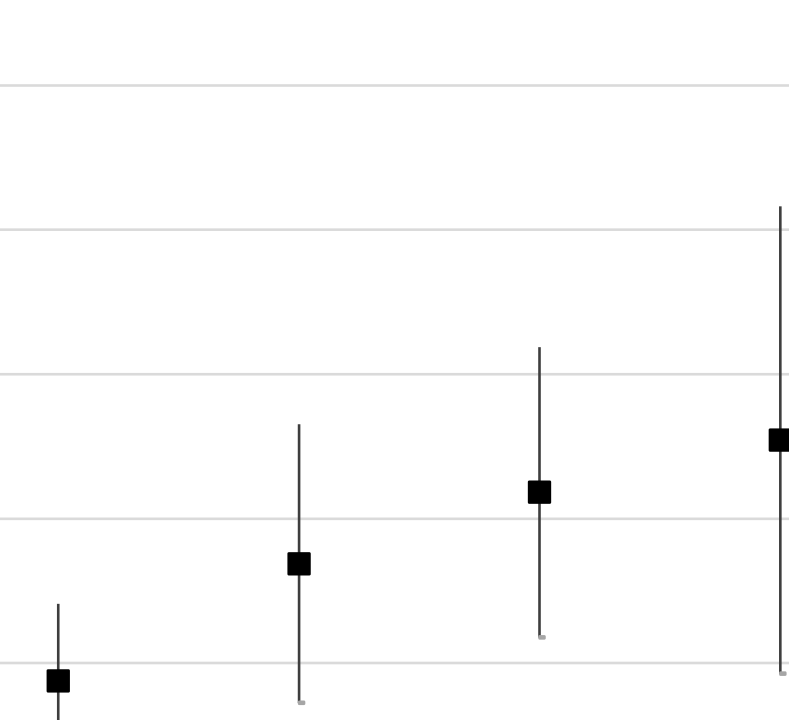

15

18

21

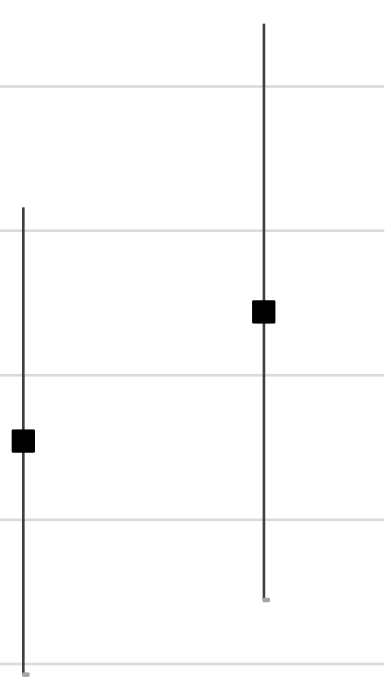

24

Scale is inverted.

Each estimate is from a separate equation.

Vertical lines represent $95 \%$ confidence intervals

Solid markers indicate significant ( $p$-value $<.05$ ) estimates.

Hollow markers indicate insignificant estimates.

Estimate - 95\% Upper Confidence 


\section{Figure 8}

Relationship across cancer sites between 1981-1995 change in POST1980\% and 1999-2013 change in In(YPLL80), controlling for changes in incidence

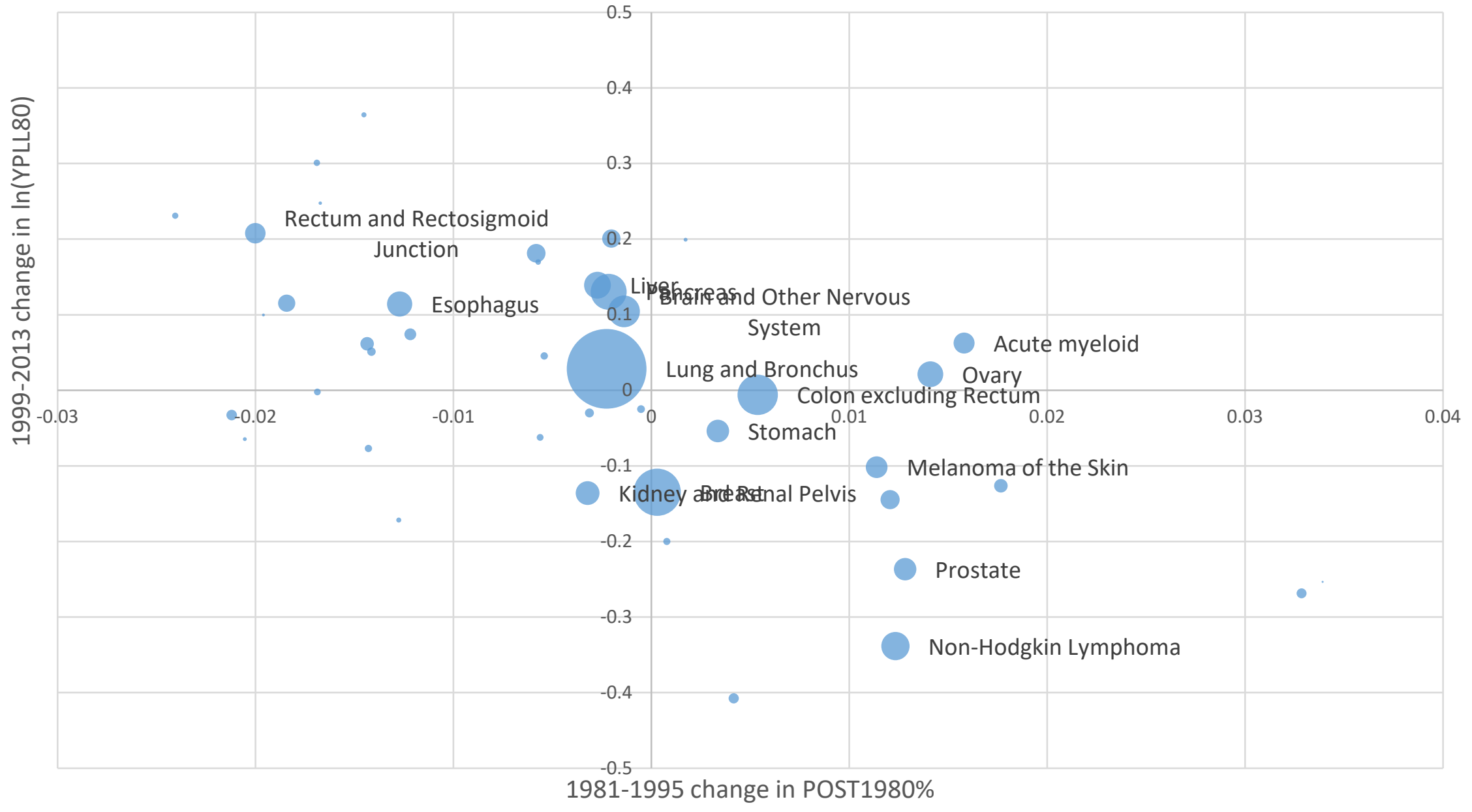

To improve legibility, only the largest (top 15), in terms of mean YPLL80, are labeled. Bubble size is proportional to mean(YPLL80). The chart plots the residuals from the regression of $\Delta \ln \left(Y P L L 80_{s t}\right)$ on $\Delta \ln \left(N_{-} D X \_10 \_Y E A R_{s t}\right)$ and $\triangle A G E \_D X \_10 \_Y E A R_{s t}$ against the residuals from the regression of $\triangle \mathrm{POST} 1980 \%_{\mathrm{s}, \mathrm{t}-18}$ on $\Delta \ln \left(\mathrm{N} \_\mathrm{DX} \_10 \_Y E A R_{\mathrm{st}}\right)$ and $\triangle \mathrm{AGE}$ _DX_10_YEAR $\mathrm{R}_{\mathrm{st}}$. 
Table 1

Estimates of $\beta_{\mathrm{k}}$ parameters of models of the 5 -year observed survival rate (eq. (1))

\begin{tabular}{|c|c|c|c|c|c|c|c|c|c|}
\hline lag & Estimate & Std. Err. & Z & $\operatorname{Pr}>|\mathrm{Z}|$ & lag & Estimate & Std. Err. & Z & $\operatorname{Pr}>|Z|$ \\
\hline \multicolumn{5}{|c|}{$\begin{array}{l}\text { A. POST1975\%; descriptor records only; all } \\
\text { cancer sites }\end{array}$} & \multicolumn{5}{|c|}{$\begin{array}{l}\text { B. POST1975\%; descriptor records only; prostate } \\
\text { cancer excluded }\end{array}$} \\
\hline 0 & -0.275 & 3.512 & -0.08 & 0.9377 & 0 & 0.602 & 2.908 & 0.21 & 0.836 \\
\hline 3 & 2.765 & 3.229 & 0.86 & 0.3918 & 3 & 1.565 & 2.649 & 0.59 & 0.5545 \\
\hline 6 & 4.433 & 2.932 & 1.51 & 0.1305 & 6 & 3.668 & 2.462 & 1.49 & 0.1362 \\
\hline 9 & 4.190 & 2.618 & 1.60 & 0.1094 & 9 & 3.242 & 2.370 & 1.37 & 0.1714 \\
\hline 12 & 8.960 & 2.720 & 3.29 & 0.001 & 12 & 7.287 & 2.793 & 2.61 & 0.0091 \\
\hline 15 & 8.979 & 2.747 & 3.27 & 0.0011 & 15 & 7.249 & 2.644 & 2.74 & 0.0061 \\
\hline 18 & 11.563 & 3.363 & 3.44 & 0.0006 & 18 & 9.036 & 3.354 & 2.69 & 0.0071 \\
\hline 21 & 20.192 & 4.708 & 4.29 & $<.0001$ & 21 & 15.487 & 5.445 & 2.84 & 0.0045 \\
\hline 24 & 21.569 & 6.878 & 3.14 & 0.0017 & 24 & 15.561 & 7.332 & 2.12 & 0.0338 \\
\hline \multicolumn{5}{|c|}{$\begin{array}{l}\text { C. POST1975\%; descriptor + supp. concept } \\
\text { records; all cancer sites }\end{array}$} & \multicolumn{5}{|c|}{$\begin{array}{l}\text { D. POST1975\%; descriptor + supp. concept } \\
\text { records; prostate cancer excluded }\end{array}$} \\
\hline 0 & -0.251 & 2.628 & -0.10 & 0.9241 & 0 & 0.291 & 2.199 & 0.13 & 0.8947 \\
\hline 3 & 1.176 & 2.024 & 0.58 & 0.5614 & 3 & 0.055 & 1.640 & 0.03 & 0.9731 \\
\hline 6 & 1.958 & 1.951 & 1.00 & 0.3158 & 6 & 1.558 & 1.535 & 1.02 & 0.3099 \\
\hline 9 & 2.881 & 1.673 & 1.72 & 0.085 & 9 & 2.011 & 1.456 & 1.38 & 0.1672 \\
\hline 12 & 4.907 & 1.706 & 2.88 & 0.004 & 12 & 3.456 & 1.834 & 1.88 & 0.0594 \\
\hline 15 & 5.718 & 1.697 & 3.37 & 0.0008 & 15 & 4.160 & 1.747 & 2.38 & 0.0172 \\
\hline 18 & 7.399 & 2.195 & 3.37 & 0.0007 & 18 & 5.425 & 2.301 & 2.36 & 0.0184 \\
\hline 21 & 10.178 & 2.931 & 3.47 & 0.0005 & 21 & 6.138 & 3.771 & 1.63 & 0.1035 \\
\hline 24 & 13.893 & 4.761 & 2.92 & 0.0035 & 24 & 8.997 & 6.620 & 1.36 & 0.1741 \\
\hline \multicolumn{5}{|c|}{$\begin{array}{l}\text { E. POST1970\%; descriptor records only; all } \\
\text { cancer sites }\end{array}$} & \multicolumn{5}{|c|}{$\begin{array}{l}\text { F. POST1980\%; descriptor records only; all } \\
\text { cancer sites }\end{array}$} \\
\hline 0 & -0.744 & 2.934 & -0.25 & 0.7997 & 0 & 0.171 & 3.022 & 0.06 & 0.955 \\
\hline 3 & 1.447 & 2.748 & 0.53 & 0.5985 & 3 & 3.143 & 3.163 & 0.99 & 0.3204 \\
\hline 6 & 2.099 & 2.623 & 0.80 & 0.4235 & 6 & 4.893 & 3.130 & 1.56 & 0.1179 \\
\hline 9 & 3.601 & 2.357 & 1.53 & 0.1267 & 9 & 5.965 & 3.436 & 1.74 & 0.0825 \\
\hline 12 & 6.884 & 2.851 & 2.41 & 0.0158 & 12 & 12.561 & 3.825 & 3.28 & 0.001 \\
\hline 15 & 5.840 & 2.668 & 2.19 & 0.0286 & 15 & 15.346 & 4.613 & 3.33 & 0.0009 \\
\hline 18 & 5.680 & 2.786 & 2.04 & 0.0414 & 18 & 23.223 & 7.814 & 2.97 & 0.003 \\
\hline 21 & 13.919 & 2.818 & 4.94 & $<.0001$ & 21 & 56.802 & 13.795 & 4.12 & $<.0001$ \\
\hline 24 & 12.608 & 3.855 & 3.27 & 0.0011 & 24 & 88.315 & 37.237 & 2.37 & 0.0177 \\
\hline
\end{tabular}

Each estimate is from a separate model. All models include $\ln \left(\mathrm{SURV} \_E X P_{\text {st }} /\left(1-\mathrm{SURV} \_E X P_{\text {st }}\right)\right), \ln \left(\mathrm{N}_{-} \mathrm{DX}\right.$ st $)$, cancer-site and year fixed effects; coefficients on these variables are not shown to conserve space. Models were estimated via weighted-least squares, weighting by $\mathrm{N}_{-} \mathrm{DX}$ st. Disturbances were clustered within cancer sites. Estimates in bold are statistically significant (p-value $<.05$ ). 
Table 2

Estimates of $\beta_{\mathrm{k}}$ parameters of models of mortality measures (eq. (2))

\begin{tabular}{|c|c|c|c|c|c|c|c|c|c|}
\hline lag & Estimate & Std. Err. & $\mathbf{Z}$ & $\operatorname{Pr}>|Z|$ & lag & Estimate & Std. Err. & $\mathbf{Z}$ & $\operatorname{Pr}>|Z|$ \\
\hline \multicolumn{5}{|c|}{ A. YPLL80; descriptor records only } & \multicolumn{5}{|c|}{ B. YPLL80; descriptor + supp. concept records } \\
\hline 0 & 3.770 & 3.039 & 1.24 & 0.2148 & 0 & 5.028 & 3.781 & 1.33 & 0.1835 \\
\hline 3 & -0.283 & 2.840 & -0.10 & 0.9205 & 3 & -0.281 & 2.114 & -0.13 & 0.8941 \\
\hline 6 & -1.456 & 2.266 & -0.64 & 0.5206 & 6 & -1.638 & 1.488 & -1.10 & 0.2709 \\
\hline 9 & -2.904 & 1.392 & -2.09 & 0.037 & 9 & -1.586 & 0.994 & -1.60 & 0.1104 \\
\hline 12 & -4.391 & 1.357 & -3.24 & 0.0012 & 12 & -2.404 & 0.991 & -2.43 & 0.0153 \\
\hline 15 & -8.445 & 2.462 & -3.43 & 0.0006 & 15 & -5.152 & 1.512 & -3.41 & 0.0007 \\
\hline 18 & -10.916 & 2.564 & -4.26 & $<.0001$ & 18 & -6.960 & 1.627 & -4.28 & $<.0001$ \\
\hline 21 & -12.720 & 4.130 & -3.08 & 0.0021 & 21 & -7.907 & 2.569 & -3.08 & 0.0021 \\
\hline 24 & -17.193 & 5.091 & -3.38 & 0.0007 & 24 & -12.500 & 3.870 & -3.23 & 0.0012 \\
\hline & & & & & & & & & \\
\hline \multicolumn{5}{|c|}{ C. YPLL70; descriptor records only } & \multicolumn{5}{|c|}{ D. YPLL70; descriptor + supp. concept records } \\
\hline 0 & 3.637 & 3.042 & 1.20 & 0.2318 & 0 & 6.893 & 3.986 & 1.73 & 0.0837 \\
\hline 3 & -0.840 & 2.946 & -0.28 & 0.7757 & 3 & -0.678 & 2.128 & -0.32 & 0.7499 \\
\hline 6 & -1.873 & 2.281 & -0.82 & 0.4116 & 6 & -1.911 & 1.519 & -1.26 & 0.2083 \\
\hline 9 & -2.729 & 1.477 & -1.85 & 0.0646 & 9 & -1.366 & 1.031 & -1.32 & 0.1853 \\
\hline 12 & -4.365 & 1.573 & -2.78 & 0.0055 & 12 & -2.258 & 1.099 & -2.05 & 0.0399 \\
\hline 15 & -8.246 & 2.527 & -3.26 & 0.0011 & 15 & -4.898 & 1.679 & -2.92 & 0.0035 \\
\hline 18 & -10.871 & 2.614 & -4.16 & $<.0001$ & 18 & -6.852 & 1.754 & -3.91 & $<.0001$ \\
\hline 21 & -12.785 & 4.335 & -2.95 & 0.0032 & 21 & -7.658 & 2.745 & -2.79 & 0.0053 \\
\hline 24 & -17.922 & 5.326 & -3.37 & 0.0008 & 24 & -12.733 & 4.136 & -3.08 & 0.0021 \\
\hline & & & & & & & & & \\
\hline \multicolumn{5}{|c|}{ E. DEATHS; descriptor records only } & \multicolumn{5}{|c|}{ F. DEATHS; descriptor + supp. concept records } \\
\hline 0 & 3.058 & 2.920 & 1.05 & 0.2949 & 0 & -0.313 & 1.594 & -0.20 & 0.8445 \\
\hline 3 & -0.008 & 2.589 & 0.00 & 0.9974 & 3 & 0.018 & 1.997 & 0.01 & 0.9927 \\
\hline 6 & -1.225 & 2.338 & -0.52 & 0.6004 & 6 & -1.370 & 1.578 & -0.87 & 0.3854 \\
\hline 9 & -2.759 & 1.409 & -1.96 & 0.0502 & 9 & -1.625 & 1.030 & -1.58 & 0.1146 \\
\hline 12 & -3.787 & 1.127 & -3.36 & 0.0008 & 12 & -2.192 & 0.880 & -2.49 & 0.0127 \\
\hline 15 & -7.239 & 2.327 & -3.11 & 0.0019 & 15 & -4.638 & 1.412 & -3.29 & 0.001 \\
\hline 18 & -8.778 & 2.371 & -3.70 & 0.0002 & 18 & -5.731 & 1.461 & -3.92 & $<.0001$ \\
\hline 21 & -10.089 & 3.687 & -2.74 & 0.0062 & 21 & -7.043 & 2.467 & -2.86 & 0.0043 \\
\hline 24 & -12.320 & 4.544 & -2.71 & 0.0067 & 24 & -9.518 & 3.354 & -2.84 & 0.0045 \\
\hline
\end{tabular}

Each estimate is from a separate model. All models include $\ln \left(\mathrm{N} \_\mathrm{DX} \_10 \_Y E A R_{\mathrm{st}}\right)$, AGE_DX_10_YEAR ${ }_{\mathrm{st}}$, cancer-site and year fixed effects; coefficients on these variables are not shown to conserve space. Models were estimated via weighted-least squares, weighting by $(1 / \mathrm{T}) \sum_{\mathrm{t}} \mathrm{MORT}_{\mathrm{st}}$. Disturbances were clustered within cancer sites. Estimates in bold are statistically significant (p-value $<.05)$. 


\section{Table 3}

Quantification of the long-run impact of new medical ideas on cancer survival and mortality

A. Impact on 5-year observed survival rate

\begin{tabular}{|c|c|c|c|}
\hline $\mathrm{k}$ & $\beta_{\mathrm{k}}$ & $\operatorname{mean}\left(\Delta\right.$ POST1975\% $\left.{ }_{\mathrm{t}-\mathrm{k}}\right)$ & $\beta_{\mathrm{k}}{ }^{*}$ mean $\left(\Delta \mathrm{POST} 1975 \%_{\mathrm{t}-\mathrm{k}}\right)$ \\
\hline 12 & 9.0 & $5.5 \%$ & 0.496 \\
\hline 15 & 9.0 & $4.4 \%$ & 0.394 \\
\hline 18 & 11.6 & $3.0 \%$ & 0.346 \\
\hline 21 & 20.2 & $1.8 \%$ & 0.373 \\
\hline 24 & 21.6 & $1.2 \%$ & 0.251 \\
\hline average & & & 0.372 \\
\hline
\end{tabular}

$\beta_{\mathrm{k}}$ estimates are from Panel A of Table 1.

B. Impact on number of years of potential life lost before age 80

\begin{tabular}{|c|c|c|c|c|}
\hline $\mathrm{k}$ & $\beta_{\mathrm{k}}$ & $\operatorname{mean}\left(\Delta \mathrm{POST} 1980 \%_{\mathrm{t}-\mathrm{k}}\right)$ & $\beta_{\mathrm{k}} *^{\text {mean }\left(\Delta \mathrm{POST} 1980 \%_{\mathrm{t}-\mathrm{k}}\right)}$ & $\begin{array}{c}\left(\beta_{\mathrm{k}} *_{\text {mean }}\left(\Delta \mathrm{POST} 1980 \%_{\mathrm{t}-\mathrm{k}}\right)\right)- \\
\text { pop. growth }\end{array}$ \\
\hline 9 & -2.9 & $5.5 \%$ & -0.158 & -0.278 \\
\hline 12 & -4.4 & $5.9 \%$ & -0.258 & -0.377 \\
\hline 15 & -8.4 & $4.5 \%$ & -0.380 & -0.499 \\
\hline 18 & -10.9 & $3.3 \%$ & -0.359 & -0.479 \\
\hline 21 & -12.7 & $2.1 \%$ & -0.269 & -0.388 \\
\hline 24 & -17.2 & $0.9 \%$ & -0.162 & -0.282 \\
\hline average & & & -0.264 & -0.384 \\
\hline
\end{tabular}

$\beta_{\mathrm{k}}$ estimates are from Panel A of Table 2. 
Appendix Table 1

MeSH Descriptors linked to Cancer Causes of Death

\begin{tabular}{|c|c|c|c|}
\hline Cancer Cause of Death & ICD-10 & MeSH Descriptor & $\begin{array}{c}\text { MeSH } \\
\text { Unique ID } \\
\end{array}$ \\
\hline Lip & $\mathrm{CO0}$ & Lip Neoplasms & D008048 \\
\hline Tongue & C01-C02 & Tongue Neoplasms & D014062 \\
\hline $\begin{array}{l}\text { Floor of Mouth, Gum } \\
\text { and Other Mouth }\end{array}$ & C03-C06 & Mouth Neoplasms & D009062 \\
\hline Salivary Gland & C07-C08 & $\begin{array}{l}\text { Salivary Gland } \\
\text { Neoplasms }\end{array}$ & D012468 \\
\hline Tonsil & C09 & Tonsillar Neoplasms & D014067 \\
\hline Oropharynx & C10 & $\begin{array}{l}\text { Oropharyngeal } \\
\text { Neoplasms }\end{array}$ & D009959 \\
\hline Nasopharynx & C11 & $\begin{array}{l}\text { Nasopharyngeal } \\
\text { Neoplasms }\end{array}$ & D009303 \\
\hline Esophagus & C15 & Esophageal Neoplasms & D004938 \\
\hline Stomach & C16 & Stomach Neoplasms & D013274 \\
\hline Small Intestine & $\mathrm{C} 17$ & Intestinal Neoplasms & D007414 \\
\hline $\begin{array}{l}\text { Colon excluding } \\
\text { Rectum }\end{array}$ & C18, C26.0 & Colonic Neoplasms & D003110 \\
\hline $\begin{array}{l}\text { Rectum and } \\
\text { Rectosigmoid Junction }\end{array}$ & C19-C20 & Rectal Neoplasms & D012004 \\
\hline $\begin{array}{l}\text { Anus, Anal Canal and } \\
\text { Anorectum }\end{array}$ & $\mathrm{C} 21$ & Anus Neoplasms & D001005 \\
\hline Liver & $\begin{array}{l}\text { C22.0, C22.2-C22.4, } \\
\text { C22.7, C22.9 }\end{array}$ & Liver Neoplasms & D008113 \\
\hline Intrahepatic Bile Duct & $\mathrm{C} 22.1$ & Bile Duct Neoplasms & D001650 \\
\hline Gallbladder & $\mathrm{C} 23$ & Gallbladder Neoplasms & D005706 \\
\hline Pancreas & $\mathrm{C} 25$ & Pancreatic Neoplasms & D010190 \\
\hline $\begin{array}{l}\text { Nose, Nasal Cavity and } \\
\text { Middle Ear }\end{array}$ & C30-C31 & Nose Neoplasms & D009669 \\
\hline Larynx & C32 & Laryngeal Neoplasms & D007822 \\
\hline Lung and Bronchus & C34 & Lung Neoplasms & D008175 \\
\hline Bones and Joints & C40-C41 & Bone Neoplasms & D001859 \\
\hline Melanoma of the Skin & C43 & Melanoma & D008545 \\
\hline $\begin{array}{l}\text { Mesothelioma (ICD-10 } \\
\text { only)+ }\end{array}$ & C45+ & Mesothelioma & D008654 \\
\hline $\begin{array}{l}\text { Kaposi Sarcoma (ICD- } \\
10 \text { only) }+\end{array}$ & C46+ & Sarcoma, Kaposi & D012514 \\
\hline $\begin{array}{l}\text { Soft Tissue including } \\
\text { Heart\$ }\end{array}$ & $\begin{array}{l}\text { C47, C49, C38.0, } \\
\text { C45.2+ }\end{array}$ & Soft Tissue Neoplasms & D012983 \\
\hline Breast & $\mathrm{C} 50$ & Breast Neoplasms & D001943 \\
\hline Vulva & C51 & Vulvar Neoplasms & D014846 \\
\hline
\end{tabular}


Appendix Table 1

MeSH Descriptors linked to Cancer Causes of Death

\begin{tabular}{|c|c|c|c|}
\hline Cancer Cause of Death & ICD-10 & MeSH Descriptor & $\begin{array}{c}\text { MeSH } \\
\text { Unique ID } \\
\end{array}$ \\
\hline Vagina & C52 & Vaginal Neoplasms & D014625 \\
\hline Cervix Uteri & C53 & $\begin{array}{l}\text { Uterine Cervical } \\
\text { Neoplasms }\end{array}$ & D002583 \\
\hline Ovary & C56 & Ovarian Neoplasms & D010051 \\
\hline Penis & $\mathrm{C} 60$ & Penile Neoplasms & D010412 \\
\hline Prostate & C61 & Prostatic Neoplasms & D011471 \\
\hline Testis & C62 & Testicular Neoplasms & D013736 \\
\hline Kidney and Renal Pelvis & C64-C65 & Kidney Neoplasms & D007680 \\
\hline Ureter & C66 & Ureteral Neoplasms & D014516 \\
\hline Urinary Bladder & C67 & $\begin{array}{l}\text { Urinary Bladder } \\
\text { Neoplasms }\end{array}$ & D001749 \\
\hline Eye and Orbit & C69 & Eye Neoplasms & D005134 \\
\hline $\begin{array}{l}\text { Brain and Other } \\
\text { Nervous System } \\
\end{array}$ & C70, C71, C72 & Brain Neoplasms & D001932 \\
\hline Thyroid & $\mathrm{C73}$ & Thyroid Neoplasms & D013964 \\
\hline Hodgkin Lymphoma & $\mathrm{C} 81$ & Hodgkin Disease & D006689 \\
\hline $\begin{array}{l}\text { Non-Hodgkin } \\
\text { Lymphoma } \\
\end{array}$ & C82-C85, C96.3 & $\begin{array}{l}\text { Lymphoma, Non- } \\
\text { Hodgkin }\end{array}$ & D008228 \\
\hline Myeloma & C90.0, C90.2 & Multiple Myeloma & D009101 \\
\hline $\begin{array}{l}\text { Acute Lymphocytic } \\
\text { Leukemia }\end{array}$ & C91.0 & $\begin{array}{l}\text { Precursor Cell } \\
\text { Lymphoblastic } \\
\text { Leukemia-Lymphoma }\end{array}$ & D054198 \\
\hline $\begin{array}{l}\text { Chronic Lymphocytic } \\
\text { Leukemia }\end{array}$ & C91.1 & $\begin{array}{l}\text { Leukemia, } \\
\text { Lymphocytic, Chronic, } \\
\text { B-Cell }\end{array}$ & D015451 \\
\hline Acute myeloid & $\begin{array}{l}\text { C92.0, C92.4-C92.5, } \\
\text { C94.0, C94.2 }\end{array}$ & $\begin{array}{l}\text { Leukemia, Myeloid, } \\
\text { Acute }\end{array}$ & D015470 \\
\hline $\begin{array}{l}\text { Chronic Myeloid } \\
\text { Leukemia }\end{array}$ & C92.1 & Leukemia, Myeloid & D007951 \\
\hline $\begin{array}{l}\text { Acute Monocytic } \\
\text { Leukemia }\end{array}$ & C93.0 & $\begin{array}{l}\text { Leukemia, Monocytic, } \\
\text { Acute }\end{array}$ & D007948 \\
\hline
\end{tabular}

\section{$\underline{\text { SEER Cause of Death Recode 1969+ }}$}


Appendix Table 2

Observed and expected 5-year survival rates, patients diagnosed in SEER 9 registries, by cancer site, 1994 and 2008

\begin{tabular}{|c|c|c|c|c|c|c|}
\hline \multirow{2}{*}{$\begin{array}{c}\text { ICD10CM } \\
\text { Year } \\
\end{array}$} & \multicolumn{2}{|c|}{$\begin{array}{l}\text { Number } \\
\text { diagnosed }\end{array}$} & \multicolumn{2}{|c|}{$\begin{array}{c}\text { Observed 5-year } \\
\text { survival rate }\end{array}$} & \multicolumn{2}{|c|}{$\begin{array}{l}\text { Expected } 5 \text {-year } \\
\text { survival rate }\end{array}$} \\
\hline & 1994 & 2008 & 1994 & 2008 & 1994 & 2008 \\
\hline C61 Prostate & 15,945 & 19,241 & $74.9 \%$ & $86.1 \%$ & $79.1 \%$ & $86.6 \%$ \\
\hline C50 Breast & 14,020 & 16,359 & $77.3 \%$ & $82.7 \%$ & $89.3 \%$ & $91.4 \%$ \\
\hline C34 Lung and Bronchus & 12,449 & 12,617 & $12.2 \%$ & $16.2 \%$ & $86.0 \%$ & $86.3 \%$ \\
\hline C18, C26.0 Colon excluding Rectum & 7,266 & 7,289 & $48.0 \%$ & $56.1 \%$ & $79.6 \%$ & $84.0 \%$ \\
\hline C82-C85, C96.3 Non-Hodgkin Lymphoma & 3,943 & 4,813 & $46.5 \%$ & $64.3 \%$ & $88.0 \%$ & $88.6 \%$ \\
\hline C67 Urinary Bladder & 3,856 & 4,439 & $64.5 \%$ & $62.7 \%$ & $80.5 \%$ & $81.0 \%$ \\
\hline C43 Melanoma of the Skin & 3,135 & 5,163 & $80.8 \%$ & $84.2 \%$ & $91.0 \%$ & $90.2 \%$ \\
\hline C19-C20 Rectum and Rectosigmoid Junction & 2,812 & 2,942 & $49.9 \%$ & $60.9 \%$ & $83.4 \%$ & $89.0 \%$ \\
\hline C90.0, C90.2 Myeloma & 2,673 & 3,174 & $45.5 \%$ & $62.5 \%$ & $88.1 \%$ & $88.9 \%$ \\
\hline C25 Pancreas & 2,112 & 2,846 & $4.0 \%$ & $6.7 \%$ & $85.1 \%$ & $88.4 \%$ \\
\hline C64-C65 Kidney and Renal Pelvis & 2,080 & 3,588 & $54.2 \%$ & $66.5 \%$ & $87.4 \%$ & $89.5 \%$ \\
\hline C16 Stomach & 1,757 & 1,652 & $17.9 \%$ & $27.2 \%$ & $81.2 \%$ & $86.0 \%$ \\
\hline C56 Ovary & 1,563 & 1,714 & $40.5 \%$ & $42.9 \%$ & $91.8 \%$ & $93.0 \%$ \\
\hline C70, C71, C72 Brain and Other Nervous System & 1,432 & 1,687 & $31.3 \%$ & $34.7 \%$ & $97.2 \%$ & $97.1 \%$ \\
\hline C73 Thyroid & 1,360 & 3,321 & $92.0 \%$ & $94.2 \%$ & $96.1 \%$ & $96.3 \%$ \\
\hline C53 Cervix Uteri & 1,097 & 917 & $68.6 \%$ & $66.7 \%$ & $95.4 \%$ & $96.2 \%$ \\
\hline C46+ Kaposi Sarcoma (ICD-10 only)+ & 933 & 171 & $16.9 \%$ & $67.9 \%$ & $95.9 \%$ & $92.2 \%$ \\
\hline C91.1 Chronic Lymphocytic Leukemia & 908 & 1,237 & $62.6 \%$ & $68.7 \%$ & $81.8 \%$ & $81.9 \%$ \\
\hline C32 Larynx & 873 & 720 & $53.6 \%$ & $56.7 \%$ & $86.3 \%$ & $88.4 \%$ \\
\hline C15 Esophagus & 843 & 1,059 & $10.8 \%$ & $16.5 \%$ & $85.6 \%$ & $88.2 \%$ \\
\hline C62 Testis & 704 & 815 & $94.4 \%$ & $95.4 \%$ & $98.3 \%$ & $98.5 \%$ \\
\hline C22.0, C22.2-C22.4, C22.7, C22.9 Liver & 688 & 1,719 & $6.2 \%$ & $18.1 \%$ & $89.1 \%$ & $91.7 \%$ \\
\hline C92.0, C92.4-C92.5, C94.0, C94.2 Acute myeloid & 663 & 827 & $13.9 \%$ & $22.9 \%$ & $95.2 \%$ & $95.5 \%$ \\
\hline C81 Hodgkin Lymphoma & 661 & 762 & $80.6 \%$ & $87.5 \%$ & $96.9 \%$ & $96.8 \%$ \\
\hline C03-C06 Gum and Other Mouth & 549 & 471 & $50.6 \%$ & $56.6 \%$ & $86.6 \%$ & $89.1 \%$ \\
\hline $\begin{array}{l}\text { C47, C49, C38.0, C45.2+ Soft Tissue including } \\
\text { Heart\$ }\end{array}$ & 546 & 759 & $57.9 \%$ & $59.7 \%$ & $90.7 \%$ & $91.3 \%$ \\
\hline C01-C02 Tongue & 465 & 755 & $48.6 \%$ & $61.8 \%$ & $89.1 \%$ & $91.9 \%$ \\
\hline C92.1 Chronic Myeloid Leukemia & 372 & 427 & $32.5 \%$ & $58.2 \%$ & $88.8 \%$ & $89.9 \%$ \\
\hline C91.0 Acute Lymphocytic Leukemia & 288 & 394 & $57.6 \%$ & $71.0 \%$ & $98.7 \%$ & $99.0 \%$ \\
\hline C23 Gallbladder & 253 & 242 & $13.6 \%$ & $17.8 \%$ & $83.6 \%$ & $81.5 \%$ \\
\hline C17 Small Intestine & 249 & 480 & $44.0 \%$ & $63.6 \%$ & $86.8 \%$ & $88.5 \%$ \\
\hline C00 Lip & 229 & 138 & $79.0 \%$ & $77.5 \%$ & $79.7 \%$ & $83.0 \%$ \\
\hline C07-C08 Salivary Gland & 223 & 297 & $61.1 \%$ & $67.2 \%$ & $85.5 \%$ & $90.4 \%$ \\
\hline C45+ Mesothelioma (ICD-10 only)+ & 223 & 198 & $7.2 \%$ & $8.1 \%$ & $86.6 \%$ & $82.2 \%$ \\
\hline C09 Tonsil & 220 & 459 & $48.2 \%$ & $66.7 \%$ & $92.4 \%$ & $93.2 \%$ \\
\hline
\end{tabular}


Appendix Table 2

Observed and expected 5-year survival rates, patients diagnosed in SEER 9 registries, by cancer site, 1994 and 2008

\begin{tabular}{|c|c|c|c|c|c|c|}
\hline \multirow{2}{*}{$\begin{array}{c}\text { ICD10CM } \\
\text { Year }\end{array}$} & \multicolumn{2}{|c|}{$\begin{array}{c}\text { Number } \\
\text { diagnosed }\end{array}$} & \multicolumn{2}{|c|}{$\begin{array}{l}\text { Observed 5-year } \\
\text { survival rate }\end{array}$} & \multicolumn{2}{|c|}{$\begin{array}{l}\text { Expected } 5 \text {-year } \\
\text { survival rate }\end{array}$} \\
\hline & 1994 & 2008 & 1994 & 2008 & 1994 & 2008 \\
\hline C51 Vulva & 219 & 269 & $62.1 \%$ & $57.0 \%$ & $81.6 \%$ & $84.0 \%$ \\
\hline C40-C41 Bones and Joints & 198 & 238 & $61.6 \%$ & $69.0 \%$ & $97.4 \%$ & $96.9 \%$ \\
\hline C21 Anus, Anal Canal and Anorectum & 181 & 404 & $55.8 \%$ & $59.6 \%$ & $85.4 \%$ & $92.0 \%$ \\
\hline C69 Eye and Orbit & 170 & 171 & $78.2 \%$ & $80.9 \%$ & $88.4 \%$ & $91.6 \%$ \\
\hline C22.1 Intrahepatic Bile Duct & 167 & 186 & $3.6 \%$ & $6.5 \%$ & $83.9 \%$ & $90.8 \%$ \\
\hline C30-C31 Nose, Nasal Cavity and Middle Ear & 143 & 169 & $51.7 \%$ & $52.5 \%$ & $86.8 \%$ & $87.8 \%$ \\
\hline C11 Nasopharynx & 139 & 174 & $58.7 \%$ & $61.7 \%$ & $94.5 \%$ & $95.5 \%$ \\
\hline C66 Ureter & 77 & 96 & $49.2 \%$ & $40.6 \%$ & $76.5 \%$ & $82.2 \%$ \\
\hline C60 Penis & 74 & 90 & $63.5 \%$ & $57.1 \%$ & $77.3 \%$ & $79.9 \%$ \\
\hline C52 Vagina & 61 & 68 & $36.1 \%$ & $36.8 \%$ & $86.7 \%$ & $86.1 \%$ \\
\hline C10 Oropharynx & 56 & 90 & $33.9 \%$ & $41.1 \%$ & $91.8 \%$ & $91.4 \%$ \\
\hline C93.0 Acute Monocytic Leukemia & 39 & 45 & $12.8 \%$ & $28.1 \%$ & $97.6 \%$ & $95.5 \%$ \\
\hline
\end{tabular}


Appendix Table 3

Mortality and incidence data, by cancer site, 1999 and 2013

\begin{tabular}{|c|c|c|c|c|c|c|c|c|c|c|}
\hline \multirow{2}{*}{$\begin{array}{l}\text { Cancer site } \\
\text { Year }\end{array}$} & \multicolumn{2}{|c|}{ YPLL80 } & \multicolumn{2}{|c|}{ YPLL70 } & \multicolumn{2}{|c|}{ Number of deaths } & \multicolumn{2}{|c|}{$\begin{array}{c}\text { Mean no. } \mathrm{dx} \text {, previous } \\
10 \text { years }\end{array}$} & \multicolumn{2}{|c|}{$\begin{array}{l}\text { Mean age at } \mathrm{dx}, \\
\text { previous } 10 \text { years }\end{array}$} \\
\hline & 1999 & 2013 & 1999 & 2013 & 1999 & 2013 & 1999 & 2013 & 1999 & 2013 \\
\hline TOTAL & $5,214,705$ & $5,449,779$ & $2,439,838$ & $2,490,520$ & 483,127 & 517,327 & 102,739 & 126,815 & & \\
\hline C34 Lung and Bronchus & $1,594,468$ & $1,520,657$ & 644,698 & 598,650 & 152,061 & 156,176 & 15,446 & 17,118 & 68.1 & 69.9 \\
\hline C50 Breast & 562,581 & 540,537 & 303,366 & 279,565 & 41,528 & 41,324 & 16,715 & 20,310 & 62.4 & 61.6 \\
\hline C18, C26.0 Colon excluding Rectum & 415,537 & 416,003 & 180,102 & 195,683 & 48,962 & 41,963 & 9,394 & 9,235 & 71.3 & 69.7 \\
\hline C25 Pancreas & 280,470 & 373,805 & 119,735 & 155,075 & 29,081 & 38,996 & 2,557 & 3,604 & 70.6 & 70.4 \\
\hline $\begin{array}{l}\text { C70, C71, C72 Brain and Other Nervous } \\
\text { System }\end{array}$ & 248,026 & 271,081 & 152,121 & 158,149 & 12,765 & 15,343 & 1,605 & 1,912 & 51.3 & 52.8 \\
\hline C82-C85, C96.3 Non-Hodgkin Lymphoma & 237,663 & 171,634 & 115,958 & 77,844 & 22,802 & 20,113 & 4,424 & 5,935 & 62.1 & 64.5 \\
\hline C56 Ovary & 159,123 & 161,010 & 76,830 & 74,445 & 13,627 & 14,276 & 1,880 & 2,043 & 62.7 & 62.8 \\
\hline C15 Esophagus & 141,068 & 170,148 & 63,325 & 74,103 & 11,917 & 14,689 & 1,048 & 1,353 & 67.5 & 68.0 \\
\hline C61 Prostate & 134,275 & 131,640 & 32,727 & 39,330 & 31,728 & 27,681 & 17,637 & 20,550 & 70.9 & 66.9 \\
\hline C16 Stomach & 132,130 & 129,683 & 63,773 & 64,283 & 12,711 & 11,261 & 2,033 & 2,131 & 69.9 & 68.5 \\
\hline C64-C65 Kidney and Renal Pelvis & 130,606 & 151,219 & 62,611 & 68,717 & 11,116 & 13,906 & 2,503 & 4,344 & 63.7 & 63.5 \\
\hline C22.0, C22.2-C22.4, C22.7, C22.9 Liver & 125,424 & 244,486 & 62,917 & 114,351 & 9,830 & 18,394 & 870 & 2,031 & 65.4 & 63.5 \\
\hline C43 Melanoma of the Skin & 113,872 & 117,513 & 64,712 & 61,348 & 7,215 & 9,394 & 3,709 & 6,490 & 56.6 & 59.8 \\
\hline $\begin{array}{l}\text { C92.0, C92.4-C92.5, C94.0, C94.2 Acute } \\
\text { myeloid }\end{array}$ & 98,445 & 112,558 & 56,202 & 58,278 & 6,932 & 9,712 & 796 & 1,084 & 61.5 & 62.8 \\
\hline C90.0, C90.2 Myeloma & 92,173 & 93,958 & 36,740 & 35,560 & 10,508 & 11,801 & 1,316 & 1,821 & 69.2 & 68.6 \\
\hline C53 Cervix Uteri & 89,690 & 90,628 & 56,623 & 55,885 & 4,204 & 4,217 & 1,228 & 1,011 & 50.4 & 50.4 \\
\hline C19-C20 Rectum and Rectosigmoid Junction & 87,573 & 123,325 & 41,075 & 62,143 & 8,260 & 9,850 & 3,539 & 3,689 & 68.1 & 64.5 \\
\hline C67 Urinary Bladder & 75,485 & 94,128 & 27,053 & 34,208 & 11,910 & 15,757 & 4,774 & 6,069 & 70.0 & 71.5 \\
\hline $\begin{array}{l}\text { C47, C49, C38.0, C45.2+ Soft Tissue } \\
\text { including HeartS }\end{array}$ & 70,699 & 82,803 & 45,109 & 51,403 & 3,684 & 4,564 & 624 & 903 & 53.9 & 56.6 \\
\hline C32 Larynx & 46,608 & 43,383 & 20,603 & 18,473 & 3,815 & 3,729 & 1,039 & 951 & 64.7 & 65.3 \\
\hline C91.0 Acute Lymphocytic Leukemia & 46,237 & 40,736 & 35,065 & 29,453 & 1,361 & 1,425 & 346 & 434 & 23.9 & 25.6 \\
\hline C40-C41 Bones and Joints & 33,968 & 35,551 & 25,115 & 25,453 & 1,224 & 1,453 & 241 & 303 & 40.4 & 42.8 \\
\hline C81 Hodgkin Lymphoma & 31,889 & 19,658 & 21,494 & 12,433 & 1,403 & 1,090 & 730 & 824 & 39.8 & 41.9 \\
\hline C92.1 Chronic Myeloid Leukemia & 29,191 & 9,825 & 17,744 & 5,358 & 1,788 & 989 & 333 & 367 & 60.5 & 58.9 \\
\hline C91.1 Chronic Lymphocytic Leukemia & 26,765 & 24,428 & 9,005 & 7,975 & 4,476 & 4,657 & 1,025 & 1,546 & 70.3 & 70.5 \\
\hline
\end{tabular}


Appendix Table 3

Mortality and incidence data, by cancer site, 1999 and 2013

\begin{tabular}{|c|c|c|c|c|c|c|c|c|c|c|}
\hline \multirow{2}{*}{\begin{tabular}{|l} 
Cancer site \\
Year \\
\end{tabular}} & \multicolumn{2}{|c|}{ YPLL80 } & \multicolumn{2}{|c|}{ YPLL70 } & \multicolumn{2}{|c|}{ Number of deaths } & \multicolumn{2}{|c|}{$\begin{array}{c}\text { Mean no. } \mathrm{dx} \text {, previous } \\
10 \text { years }\end{array}$} & \multicolumn{2}{|c|}{$\begin{array}{l}\text { Mean age at } \mathrm{dx} \text {, } \\
\text { previous } 10 \text { years }\end{array}$} \\
\hline & 1999 & 2013 & 1999 & 2013 & 1999 & 2013 & 1999 & 2013 & 1999 & 2013 \\
\hline C22.1 Intrahepatic Bile Duct & 26,293 & 63,498 & 11,978 & 28,423 & 2,552 & 5,638 & 180 & 254 & 70.8 & 69.0 \\
\hline C01-C02 Tongue & 24,785 & 31,005 & 12,953 & 15,288 & 1,738 & 2,208 & 582 & 948 & 62.4 & 61.8 \\
\hline C45+ Mesothelioma (ICD-10 only)+ & 21,193 & 18,150 & 8,033 & 6,478 & 2,338 & 2,493 & 255 & 279 & 69.6 & 72.4 \\
\hline C23 Gallbladder & 17,680 & 20,150 & 7,253 & 8,365 & 2,059 & 2,160 & 289 & 327 & 72.5 & 71.2 \\
\hline C03-C06 Gum and Other Mouth & 15,250 & 13,800 & 7,495 & 6,330 & 1,395 & 1,332 & 688 & 641 & 65.0 & 66.1 \\
\hline C62 Testis & 14,230 & 13,408 & 10,670 & 9,838 & 378 & 383 & 693 & 831 & 34.6 & 35.4 \\
\hline C73 Thyroid & 12,620 & 17,585 & 5,958 & 7,723 & 1,241 & 1,850 & 1,479 & 3,664 & 47.2 & 49.9 \\
\hline C17 Small Intestine & 12,403 & 13,310 & 6,218 & 6,085 & 1,036 & 1,270 & 372 & 645 & 65.5 & 65.5 \\
\hline C11 Nasopharynx & 11,954 & 11,335 & 7,077 & 6,323 & 638 & 643 & 170 & 197 & 54.7 & 55.1 \\
\hline C09 Tonsil & 8,780 & 12,815 & 4,590 & 6,170 & 543 & 839 & 285 & 517 & 60.3 & 58.5 \\
\hline C10 Oropharynx & 7,730 & 12,458 & 3,690 & 5,900 & 600 & 906 & 71 & 110 & 63.7 & 62.7 \\
\hline C21 Anus, Anal Canal and Anorectum & 6,838 & 13,605 & 3,818 & 7,020 & 462 & 900 & 269 & 496 & 63.3 & 61.4 \\
\hline C07-C08 Salivary Gland & 6,708 & 8,923 & 3,293 & 4,243 & 656 & 886 & 276 & 375 & 61.3 & 61.5 \\
\hline C30-C31 Nose, Nasal Cavity and Middle Ear & 6,503 & 6,072 & 3,615 & 3,187 & 456 & 443 & 167 & 200 & 63.2 & 62.1 \\
\hline C51 Vulva & 4,805 & 8,118 & 2,060 & 3,915 & 762 & 1,003 & 296 & 387 & 68.6 & 67.3 \\
\hline C52 Vagina & 3,505 & 3,740 & 1,760 & 1,658 & 403 & 437 & 92 & 114 & 68.0 & 66.7 \\
\hline C69 Eye and Orbit & 3,321 & 4,005 & 1,983 & 2,100 & 227 & 319 & 199 & 241 & 53.9 & 55.5 \\
\hline C60 Penis & 2,163 & 3,195 & 1,025 & 1,553 & 202 & 270 & 74 & 100 & 69.0 & 68.5 \\
\hline C66 Ureter & 2,138 & 2,363 & 733 & 763 & 345 & 434 & 131 & 167 & 71.8 & 73.7 \\
\hline C93.0 Acute Monocytic Leukemia & 1,467 & 1,252 & 815 & 700 & 136 & 94 & 55 & 69 & 58.9 & 58.5 \\
\hline C00 Lip & 385 & 595 & 130 & 293 & 52 & 59 & 305 & 197 & 68.7 & 68.5 \\
\hline
\end{tabular}

